\title{
Reliable Correlation for Liquid-Liquid Equilibria Outside the Critical Region
}

\author{
Ruszczynski, Lukasz; Zubov, Alexandr; O’Connell, John P.; Abildskov, Jens
}

Published in:

Journal of Chemical and Engineering Data

Link to article, DOI:

10.1021/acs.jced.7b00164

Publication date:

2017

Document Version

Peer reviewed version

Link back to DTU Orbit

Citation (APA):

Ruszczynski, L., Zubov, A., O'Connell, J. P., \& Abildskov, J. (2017). Reliable Correlation for Liquid-Liquid Equilibria Outside the Critical Region. Journal of Chemical and Engineering Data, 62(9), 2842-2854. https://doi.org/10.1021/acs.jced.7b00164

\section{General rights}

Copyright and moral rights for the publications made accessible in the public portal are retained by the authors and/or other copyright owners and it is a condition of accessing publications that users recognise and abide by the legal requirements associated with these rights.

- Users may download and print one copy of any publication from the public portal for the purpose of private study or research.

- You may not further distribute the material or use it for any profit-making activity or commercial gain

- You may freely distribute the URL identifying the publication in the public portal 


\title{
Reliable Correlation for Liquid-Liquid Equilibria
}

\section{Outside the Critical Region}

\author{
Łukasz Ruszczyński ${ }^{\mathrm{a}}$, Alexandr Zubov ${ }^{\mathrm{a}}$, John P. O’Connell ${ }^{\mathrm{b}}$, Jens Abildskov a, \\ a PROSYS, Department of Chemical and Biochemical Engineering, Building 229, \\ Technical University of Denmark, 2800 Kgs. Lyngby, Denmark \\ ${ }^{\mathrm{b}}$ Department of Chemical Engineering, University of Virginia, 102 Engineers' Way, Charlottesville, \\ Virginia 22904-4741, United States \\ *E-mail: ja@kt.dtu.dk
}

\begin{abstract}
A simple model for binary liquid-liquid equilibrium data correlation is explored. The model describes liquid-liquid equilibrium in terms of Henry's law and unsymmetrically normalized activity coefficients in each phase. A procedure for parameter estimation including an approach to initial guesses, uncertainty analysis of regression results, obtained parameters, and predicted mole fractions has been formulated. The procedure is applied to 3 cases: Hydrocarbons + water, ionic liquids + water, and nitroethane + hydrocarbons. The model has 4 parameters in the most basic formulation. Depending upon the available data, this number can be extended in a systematic fashion. We compare results of correlation to results obtained with a 4-parameter NRTL equation and COSMO-SAC. In general, the new model does nearly as well as NRTL. Advantages of the presented model are a simple form, a parameter set that can be extended in a systematic fashion with an interpretation in terms of thermodynamic properties. The model may be suitable for validation of experimental data.
\end{abstract}




\section{Introduction}

The knowledge of reliable thermodynamic properties of multicomponent systems is of central importance in chemical engineering. Liquid-liquid equilibrium (LLE) is an important thermodynamic phenomenon in a wide range of downstream separations and formulated products.

Nearly 40 years after the publication of the DECHEMA volumes on LLE of Sørensen and $\mathrm{Arlt}^{1}$, the correlation and prediction of LLE using models for liquid phase non-idealities still has significant issues ${ }^{2}$. In addition to model inadequacies - a problem which extensive research efforts have addressed unreliable and conflicting data often prevent conclusions about system and model behavior. Many data exist in the literature and new data appear at a significant rate. To maximize the value of new measurements, methods for data validation are needed ${ }^{3}$. Sørensen and Arlt addressed the issue of erroneous data to some extent. For example, data were excluded from their compilation when the sum of concentrations in a given phase differed significantly from 100 mole per cent.

When a subset of the experimental variables can be calculated from the other experimental variables, a data consistency test becomes possible. For low pressure binary vapor-liquid equilibria (VLE), this has been established for many years because the rigorous Gibbs-Duhem equation can be applied to activity coefficients from TPxy data ${ }^{4,5}$. However, classical thermodynamics alone offers no method to evaluate the quality of a given set of binary LLE Tx data.

Solid-liquid equilibrium (SLE) data validation was explored by Cunico et al. ${ }^{6}$. They used an expansion of non-ideality about infinite dilution based on fluctuation solution theory (FST). This theory of solutions was first introduced by Kirkwood and Buff in $1951^{7}$. It was later expanded by $\mathrm{O}^{\prime}$ Connell ${ }^{8}$, to establish a form of the equations equivalent to the Porter model for unsymmetric convention activity coefficients $^{9,10}$. In the simplest version of the FST-based model for the temperature of binary SLE, a 
correlation with up to three parameters was employed ${ }^{6}$. These included 2 parameters $(a, b)$ for a temperature dependent expression for Henry's law constants or activity coefficients at infinite dilution, and a parameter $(c)$ for concentration dependence of solute non-ideality relative to infinite dilution. The regression strategy was to fix $c$ at a constant value and estimate only two parameters $(a$ and $b)$ at a time. Then $c$ was varied until minimum of the objective function for correlating the data was found.

Here we report initial steps for validating the temperature dependence of binary LLE based on similar concepts. We formulate LLE with the unsymmetric convention for normalizing activity coefficients of dilute species. For cases of very dilute phases (mole fractions less than 0.01), there normally need to be only parameters for the temperature dependence of the Henry's law constants of the dilute component in each coexisting phase. At higher concentrations of the dilute component (mole fractions between 0.01 and 0.1 ), an additional parameter was introduced. Our correlation strategy is like that of Cunico et al. ${ }^{6}$. In addition, uncertainties of parameter estimates as well as of predicted compositions are provided using information related to the covariance matrix of the estimation problem. 


\section{Theory}

Here we outline the modeling approaches of this paper. Since the treatment of the equilibrium relations may be unfamiliar, we develop the relations in some detail; additional coverage can be found in the books by O'Connell/Haile ${ }^{9}$ and Prausnitz, et al. ${ }^{10}$.

\subsection{Fugacity Expressions}

The binary LLE problem consists of solving a set of two equilibrium equations, expressed as follows:

$$
\begin{aligned}
& f_{1}^{\alpha}\left(T, p, x_{1}^{\alpha}\right)=f_{1}^{\beta}\left(T, p, x_{1}^{\beta}\right) \\
& f_{2}^{\alpha}\left(T, p, x_{2}^{\alpha}\right)=f_{2}^{\beta}\left(T, p, x_{2}^{\beta}\right)
\end{aligned}
$$

It is common to employ pure component standard state fugacities for the components in both phases $\alpha$ and $\beta$. Here we will use different standard states for the components in the phases. Thus, if phase $\alpha$ is rich in component 1 and phase $\beta$ is rich in component 2 , then the phase equilibrium relationships are the following:

$$
\begin{gathered}
x_{1}^{\alpha} \gamma_{1}\left(T, x_{1}^{\alpha}\right) f_{1}\left(T, x_{1}=1\right)=x_{1}^{\beta} \frac{\gamma_{1}\left(T, x_{1}^{\beta}\right)}{\gamma_{1}\left(T, x_{1}=0\right)} \lim _{x_{1}=0} \frac{f_{1}\left(T, x_{1}=0\right)}{x_{1}} \\
\left(1-x_{1}^{\alpha}\right) \frac{\gamma_{2}\left(T, x_{1}^{\alpha}\right)}{\gamma_{2}\left(T, x_{1}=1\right)} \lim _{x_{2}=0} \frac{f_{2}\left(T, x_{2}=0\right)}{x_{2}}=\left(1-x_{1}^{\beta}\right) \gamma_{2}\left(T, x_{1}^{\beta}\right) f_{2}\left(T, x_{2}=1\right)
\end{gathered}
$$

We have omitted the Poynting factor for pressure dependence, in these forms, since pressure is rarely of concern in LLE. These equations are to be solved for two of the three variables: $T, x_{1}^{\alpha}, x_{1}^{\beta}$. Introducing Henry's law constants,

$$
H_{i j}=\lim _{x_{j}=1} \frac{f_{i}\left(T, x_{i}=0\right)}{x_{i}} \quad(i \neq j)
$$

and taking logarithms gives: 


$$
\begin{aligned}
& \ln \left[x_{1}^{\alpha} \gamma_{1}\left(T, x_{1}^{\alpha}\right)\right]=\ln \left[x_{1}^{\beta} \frac{\gamma_{1}\left(T, x_{1}^{\beta}\right)}{\gamma_{1}\left(T, x_{1}=0\right)}\right]+\ln \frac{H_{12}(T)}{f_{1}\left(T, x_{1}=1\right)} \\
& \ln \left[\left(1-x_{1}^{\alpha}\right) \frac{\gamma_{2}\left(T, x_{1}^{\alpha}\right)}{\gamma_{2}\left(T, x_{1}=1\right)}\right]+\ln \frac{H_{21}(T)}{f_{2}\left(T, x_{2}=1\right)}=\ln \left[\left(1-x_{21}^{\beta}\right) \gamma_{2}\left(T, x_{1}^{\beta}\right)\right]
\end{aligned}
$$

Note that,

$$
\begin{aligned}
& \gamma_{1}^{\infty}(T)=\gamma_{1}\left(T, x_{1}=0\right)=\frac{H_{12}}{f_{1}\left(T, x_{1}=1\right)} \\
& \gamma_{2}^{\infty}(T)=\gamma_{2}\left(T, x_{1}=1\right)=\frac{H_{21}}{f_{2}\left(T, x_{2}=1\right)}
\end{aligned}
$$

Introduction of unsymmetrically normalized activity coefficients, $\gamma_{i}^{*}$, gives:

$$
\begin{aligned}
& \ln \left[x_{1}^{\alpha} \gamma_{1}\left(T, x_{1}^{\alpha}\right)\right]=\ln \left[x_{1}^{\beta} \gamma_{1}^{*}\left(T, x_{1}^{\beta}\right)\right]+\ln \gamma_{1}^{\infty}(T) \\
& \ln \left[\left(1-x_{2}^{\alpha}\right) \gamma_{2}^{*}\left(T, x_{1}^{\alpha}\right)\right]+\ln \gamma_{2}^{\infty}(T)=\ln \left[\left(1-x_{1}^{\beta}\right) \gamma_{2}\left(T, x_{1}^{\beta}\right)\right]
\end{aligned}
$$

FST provides the following expansion ${ }^{8}$ of the unsymmetric activity coefficient for the components in phase $\beta$ :

$$
\begin{aligned}
& \ln \gamma_{1}^{*}\left(T, x_{1}^{\beta}\right)=-h_{2}^{0 \beta}(T)\left[2 x_{1}^{\beta}-\left(x_{1}^{\beta}\right)^{2}\right]-h_{3}^{0 \beta}(T)\left[\frac{3}{2}\left(x_{1}^{\beta}\right)^{2}-\left(x_{1}^{\beta}\right)^{3}\right]-\ldots \\
& \ln \gamma_{2}\left(T, x_{1}^{\beta}\right)=h_{2}^{0 \beta}(T)\left(x_{1}^{\beta}\right)^{2}+h_{3}^{0 \beta}(T)\left(x_{1}^{\beta}\right)^{3}+\ldots
\end{aligned}
$$

Here $h_{2}^{0}$ and $h_{3}^{0}$ are related to integrals of infinite dilution molecular (total or direct) correlation functions. This combination of expressions, employed for 1 and 2, satisfies the Gibbs/Duhem equation. In fact, the form employed for species $2(7 b)$ is derived from the form employed for species 1 (7a), using the 
Gibbs/Duhem equation. These relations are also used for phase $\alpha$ where the component identities are switched.

The infinite dilution activity coefficient is a function only of temperature. Seeking simplicity, we follow the approach of Cunico ${ }^{6}$ and model it with 2 parameters per phase, $a$ and $b$, using the form

$$
\ln \gamma_{1}^{\beta \infty}=a^{\beta}+\frac{b^{\beta}}{T} \quad, \quad \ln \gamma_{2}^{\alpha \infty}=a^{\alpha}+\frac{b^{\alpha}}{T}
$$

For cases of very dilute phases $\left(0.01>x_{i}\right)$ the composition effect can be ignored $\left(\gamma_{i}^{*} \approx 1\right)$. For dilute compositions $\left(0.01<x_{i}<0.10\right)$ the non-ideality should be small, so the expansion of eq. (7) can be truncated to one term $\left(h_{3}^{0} \ldots=0\right)$. Cunico et al. ${ }^{6}$ implemented the temperature dependence

$$
h_{2}^{0 \alpha}=-\frac{c^{\alpha}}{T}, \text { and } h_{2}^{0 \beta}=-\frac{c^{\beta}}{T}
$$

The modeling expressions are thus:

$$
\begin{aligned}
& \ln \gamma_{1}^{\alpha}=-\frac{c^{\alpha}}{T}\left(x_{2}^{\alpha}\right)^{2}=-\frac{c^{\alpha}}{T}\left(1-x_{1}^{\alpha}\right)^{2} \\
& \ln \gamma_{2}^{\alpha *}=-\frac{c^{\alpha}}{T}\left[\left(x_{2}^{\alpha}\right)^{2}-2 x_{2}^{\alpha}\right]=\frac{c^{\alpha}}{T}\left[1-\left(x_{1}^{\alpha}\right)^{2}\right] \\
& \ln \gamma_{2}^{\alpha, \infty}=a^{\alpha}+\frac{b^{\alpha}}{T}, \\
& \ln \gamma_{1}^{\beta *}=\frac{c^{\beta}}{T}\left[2 x_{1}^{\beta}-\left(x_{1}^{\beta}\right)^{2}\right]=\frac{c^{\beta}}{T}\left[1-\left(x_{2}^{\beta}\right)^{2}\right] \\
& \ln \gamma_{2}^{\beta}=-\frac{c^{\beta}}{T}\left(x_{1}^{\beta}\right)^{2}=-\frac{c^{\beta}}{T}\left(1-x_{2}^{\beta}\right)^{2}, \\
& \ln \gamma_{1}^{\beta, \infty}=a^{\beta}+\frac{b^{\beta}}{T} .
\end{aligned}
$$


The final equilibrium relations for correlation LLE in dilute phases are:

$$
\begin{gathered}
\ln x_{1}^{\alpha}-\frac{c^{\alpha}}{T}\left(1-x_{1}^{\alpha}\right)^{2}=\ln x_{1}^{\beta}+\frac{c^{\beta}}{T}\left[2 x_{1}^{\beta}-\left(x_{1}^{\beta}\right)^{2}\right]+a^{\beta}+\frac{b^{\beta}}{T} \\
\ln \left(1-x_{1}^{\alpha}\right)+\frac{c^{\alpha}}{T}\left[1-\left(x_{1}^{\alpha}\right)^{2}\right]+a^{\alpha}+\frac{b^{\alpha}}{T}=\ln \left(1-x_{1}^{\beta}\right)-\frac{c^{\beta}}{T}\left(x_{1}^{\beta}\right)^{2}
\end{gathered}
$$

The total number of parameters in here is six. The method will be to estimate the significant parameters and then solve equation (15) to find compositions of both components in each phase. The Methodology section below fully describes our strategy for parameter estimation. Briefly, we systematically choose values of $c^{\alpha}$ and $c^{\beta}$ independently. Then with $\left(c^{\alpha}, c^{\beta}\right)$ fixed, we regress $a$ and $b$, update $\left(c^{\alpha}, c^{\beta}\right)$, until the minimum of an objective function (defined below) is found. The ranges of $c$ values to be explored will be determined from estimates of a predictive method such as COSMO-SAC ${ }^{11}$, as outlined below.

\subsection{Parameter/Property Connections}

Properties with a straightforward connection to the model parameters are the first composition derivative of the natural logarithm of the activity coefficient $\left(d \ln \gamma_{1} / d x_{1}\right)_{T, P, N_{2}}$, which can be connected to the $c$ parameter expression in the model by:

$$
\begin{aligned}
& \frac{2 c^{\beta}}{T}=\left(\frac{d \ln \gamma_{1}^{\beta}}{d x_{1}}\right)_{T, P, N_{2}}^{\infty} \\
& \frac{2 c^{\alpha}}{T}=\left(\frac{d \ln \gamma_{2}^{\alpha}}{d x_{2}}\right)_{T, P, N_{1}}^{\infty}
\end{aligned}
$$

Values of the parameter $b$ can also be estimated using COSMO-SAC. It is proportional to the first temperature derivative of an infinite dilution activity coefficient, i.e. the partial molar excess enthalpy at infinite dilution, 


$$
b^{\alpha} \cong\left[\frac{d \ln \gamma_{2}^{\alpha}}{d(1 / T)}\right]^{\infty} \quad, \quad b^{\beta} \cong\left[\frac{d \ln \gamma_{1}^{\beta}}{d(1 / T)}\right]^{\infty}
$$

These relationships are only used to formulate initial guesses for parameters using predictive models. Using $(b, c)$ values from auxiliary data in the unsymmetric model formulation has not been examined extensively, but will be addressed more completely in the Discussion section,

\subsection{COSMO-SAC}

We employ various methods for LLE calculations. One of these is the COSMO-SAC ${ }^{11}$ model based on the COSMO-RS model originally developed by $\mathrm{Klamt}^{12}$. Molecular structure optimization is done using density functional theory (DFT) with the hybrid exchange-correlation functional B3LYP (Becke, 3parameter, Lee-Yang-Parr) at the $6-311 \mathrm{G}(\mathrm{d}, \mathrm{p})$ basis set. The quantum-chemical calculations are conducted using Gaussian09 Revison D.01. Based on the equilibrium geometry of molecule, a quantumchemical calculation (COSMO) is performed in an ideal conductor to calculate the screening charge densities on the cavities of the molecules. The resulting screening charge densities (expressed in the "sigma profile") are then used, together with general interaction energy terms, in a model of pairwise independently interacting surface segments. These are then used to obtain activity coefficients of all components in a mixture. A more detailed description of the model is given by Hsieh et al. ${ }^{11}$. 


\section{Methodology}

The following steps are involved in data correlation using the model described above as summarized in Fig. 1.

\subsection{Graphical analysis of experimental data}

For binary LLE, experimental data are usually binodal compositions in one or both phases (e.g. expressed most often in mole fractions) as a function of temperature. If the component is nearly pure in one phase and dilute in the other phase, equation (15) reduces to

$$
\begin{aligned}
& \ln x_{1}^{\alpha} \gamma_{1}^{\alpha} \approx 0=\ln x_{1}^{\beta}+\left(a^{\beta}+\frac{b^{\beta}}{T}\right) \\
& \ln x_{2}^{\beta} \gamma_{2}^{\beta} \approx 0=\ln x_{2}^{\alpha}+\left(a^{\alpha}+\frac{b^{\alpha}}{T}\right)
\end{aligned}
$$

With this approximation, $\ln x_{i}$ will be a linear function of inverse temperature; this is often found in practice, even at moderate mole fractions. An example is shown in Fig. 2, where toluene/water data ${ }^{13}$ for the dilute components have been fitted to estimate the $(a, b)$ parameters (in both phases)

$$
\begin{aligned}
& \ln x_{1}^{\beta}=-\left(a^{\beta}+\frac{b^{\beta}}{T}\right) \\
& \ln x_{2}^{\alpha}=-\left(a^{\alpha}+\frac{b^{\alpha}}{T}\right)
\end{aligned}
$$

The values obtained in this way provide initial estimates for further regressions.

$$
\text { 3.2 Regression of } a^{\alpha}, a^{\beta}, b^{\alpha}, b^{\beta} \text { with fixed values of } c^{\alpha} \text { and } c^{\beta}
$$


This step regresses the $(a, b)$ parameters in both phases, with different combinations of fixed $c^{\alpha}$ and $c^{\beta}$ parameters. With $c^{\alpha}$ and $c^{\beta}$ fixed at a given set of values, we minimize an objective function defined as the sum of the squared differences between the experimental and calculated phase mole fractions:

$$
o b j=\min \sum_{i=1}^{N} \sum_{\omega=\alpha}^{\beta}\left(x_{i}^{\omega, \exp }-x_{i}^{\omega, c a l c}\right)^{2}
$$

The objective function value, of course, depends on the values of $c^{\alpha}$ and $c^{\beta}$. Minimizing obj for different combinations of fixed $c^{\alpha}$ and $c^{\beta}$ allows us to plot in two dimensions obj as a function of $c^{\alpha}$ and $c^{\beta}$. Such an objective function surface plot, as a function of some range of $c^{\alpha}$ and $c^{\beta}$ values, will yield a minimum that locates the pair of $c$ parameters $\left(c^{\alpha}\right.$ and $\left.c^{\beta}\right)$ that produces the best agreement with experimental data.

Fig. 3 shows an example of this procedure for the toluene/water system. In Fig. 3a, the ranges of $c$-values explored are:

$-10^{6}<c^{\alpha}<10^{6} \quad, \quad-10^{4}<c^{\beta}<10^{4}$

The colors indicate the calculated objective function with blue being smallest. COSMO-SAC predicts the values (as indicated by the green squared symbol)

$c^{\alpha} \sim-0.2 \cdot 10^{6}, c^{\beta} \sim-0.75 \cdot 10^{4}$

However, the minimization of the $(a, b)$ parameters gives the lowest objective function with $c$ values that cannot be distinguished from zero on this plot. Fig. 3b shows objective function values for narrower ranges of $c$-values

$-10^{2}<c^{\alpha}<10^{2}, \quad-10^{2}<c^{\beta}<10^{2}$

Since the precise optimal $c$-values also cannot be determined with the scale of this plot, zooming closer (Fig. 3c) finally shows the optimum parameters are about 
$c^{\alpha} \sim-0.4, \quad c^{\beta} \sim 1$

These are nearly zero (and indeed small compared to the COSMO-SAC predictions) and the minimum is quite flat. This suggests that the $c$-parameters are not very important to the representation of the toluene/water binary. This is not unexpected, since the mutual solubilities are very low. If, in addition to regression of $4(a, b)$ parameters with the $c$ 's fixed, regression by mathematical optimization is done for all 6 parameters $(a, b, c)$, then the confidence intervals for the $c$-parameters from the two analyses can be compared, to evaluate if the $c$-parameters can be determined from a given data set. For the present toluene/water set, the $c$-parameters cannot be identified in this way, since as shown later, the parameter confidence intervals greatly exceed the parameter values found by optimization. Thus 4 parameters can be identified for this system.

Furthermore, liquid-liquid equilibrium systems with strong positive deviation from Raoult's law should in general not produce positive $c$-values. The above merely shows the results of an optimization study. In the following we have put in parenthesis the cases where $c$ is positive by optimization. For low concentrations, the influence of $c$ is not very strong, and its impact on the objective function is small. This is also the basis for our method of determining $c$ (Fig. 1). When the contribution from the nonideality term is not significant, or $c$ has unphysical values, parameter $c$ should not be used.

\subsection{Model uncertainty analysis}

In order to calculate $95 \%$ confidence intervals of estimated parameters, the covariance matrix $\operatorname{COV}(\theta)$ of the parameter estimates is used ${ }^{14}$ :

$$
\operatorname{COV}(\theta)=\frac{s s e}{d f}\left(J(\theta)^{T} \cdot J(\theta)\right)^{-1}
$$


Here sse is the value of the objective function. The degrees of freedom calculated as the difference between the number of experimental data points and number of estimated parameters is identified as $d f$, while $J$ is the Jacobian matrix (or local sensitivity matrix). The confidence interval of the parameters vector at $\alpha_{t}$ significance level is given as:

$\theta_{1-\alpha, t}=\theta \pm \sqrt{\operatorname{diag}(\operatorname{COV}(\theta))} \cdot t\left(d f, \alpha_{t} / 2\right)$

Here, $t\left(d f, \alpha_{t} / 2\right)$ is the $t$-distribution value corresponding to the $\alpha_{t} / 2$ percentile with $d f$ degrees of freedom. The pairwise correlation between parameters is given as follows:

$$
\operatorname{CoR}\left(\theta_{\mathrm{k}}, \theta_{1}\right)=\frac{\operatorname{COV}\left(\theta_{\mathrm{k}}, \theta_{1}\right)}{\sqrt{\sigma_{\theta_{\mathrm{k}}}^{2} \sigma_{\theta_{1}}^{2}}}
$$

To estimate the uncertainty of predicted compositions expressed in mole fractions by the model, the covariance matrix of the parameters, as well as the sensitivity matrix of the model, are used. To calculate $95 \%$ confidence intervals of the predicted compositions the following equation is used:

$$
x_{i, 1-\alpha, t}=x_{i} \pm \sqrt{\operatorname{diag}\left(J(\theta) \cdot \operatorname{COV}(\theta) \cdot J(\theta)^{T}\right)} \cdot t\left(d f, \alpha_{t} / 2\right)
$$

Fig. 4 shows an example of uncertainty plots for the toluene/water binary. The fit to the data is good with the $95 \%$ confidence limits of similar widths. Note that the data point at $x_{1}=0.989$ seems inconsistent with the others. 


\section{Results for Three Classes of Systems}

Three types of systems have been chosen for testing this model with experimental data. Except for systems of hydrocarbons and water, all data were taken from a single work. In case of hydrocarbons plus water systems, data were taken from different research groups, mainly from the compilations of data of Mączyński and Shaw ${ }^{15,16,17}$ who distinguished among reliable, tentative and doubtful data. Here only data marked as recommended and tentative were used.

\subsection{Hydrocarbon + water systems}

The first examples consist of systems with very wide miscibility gaps. Such LLE phase diagrams appear for water and a non-polar organic compound with a long alkyl chain such as hydrocarbons. Since this case deals with very dilute phases (mole fractions less than 0.01 ) we may expect that there will be two parameters per coexisting phase (4 in total), though we do regress with six parameters. Our examples in this category cover toluene + water $^{13}$ and $n$-alkanes $\left(\mathrm{C}_{5}-\mathrm{C}_{8}\right)+$ water $^{15,16,17}$.

Optimized parameters along with their uncertainty calculated using equation (26) for all systems are shown in Table 1 (row 1-5). We follow the strategy of Fig. 1 by regressing four parameters ( $a$ and $b$ for both phases) with fixed values of two $c$ parameters and initial estimates of $a$ and $b$ from a graph of the experimental data as in Fig. 2. Table 2 compares optimized values with initial guesses from graphical analysis. As can be seen, agreement is quite good in most cases. Then the values of $\left(c^{\alpha}, c^{\beta}\right)$ are varied systematically, and objective function contour plots as in Fig. 3a-c for water/toluene are prepared. Very shallow minima are found in the vicinity of $\left(c^{\alpha}, c^{\beta}\right) \sim(0,0)$. Thus, each phase can be described with only 2 parameters and the $c$-parameters are irrelevant.

Simultaneous regression of all six parameters was also done for each system. A set of values are listed in Table 7 for the toluene, n-hexane and n-heptane systems. It turns out that both $c$ parameters have very wide confidence intervals indicating again that composition effects play an insignificant role, and 
activity coefficients are equivalent to infinite dilution activity coefficients. Fig. 5 presents the experimental data (water/n-hexane) and graphs correlated with the model and confidence intervals. Most of the points are included in the $95 \%$ confidence interval calculated by Eq. (28).

\subsection{Ionic liquids + water systems}

Systems with ionic liquids (ILs) have received much attention in recent years, especially those with water where there may be significant miscibility ${ }^{18-21}$. Two systems with imidazolium-based ionic liquids, namely hexyl-3-methylimidazolium tetrafluoroborate $\left([\mathrm{hmim}]\left[\mathrm{BF}_{4}\right]\right)$ and octyl-3-methylimidazolium tetrafluoroborate $\left([\mathrm{omim}]\left[\mathrm{BF}_{4}\right]\right)$, were studied $^{18}$. The miscibility gap is not so wide and the variations of composition with temperature are great, so the $c$-parameter for composition effects in the model can be expected to be important. The COSMO-SAC estimates gave very large values, with $c^{\alpha}<<0$ and $c^{\beta}>>0$. On the scale of the upper part of Fig. 7 , the objective function minimum is near $(0,0)$. Zooming in, the minimum is actually $\left(c^{\alpha}, c^{\beta}\right) \sim(-5,0)$. This happens because the $\beta$ phase is dilute, though the $\alpha$ phase is not. Of importance is that all data points are within the $95 \%$ confidence interval (Fig. 6). Independent regression for all six parameters was also conducted for the $[\mathrm{hmim}]\left[\mathrm{BF}_{4}\right]$ system (Table 7$)$. It turns out that both $c$ parameters have non-zero values and quite wide confidence intervals, though smaller than for the hydrocarbon systems. This confirms that the nonideality term has more effect here than in the hydrocarbon systems, but it is still not very significant.

\subsection{Hydrocarbon + nitroethane systems}

The case studies above had at least one of the phases being dilute. Systems with relatively wide miscibility gap and strong dependence of temperature and composition are now considered. Four systems containing nitroethane plus an alkane ( $n$-hexane; $n$-octane; 2,2,4-trimethylpentane; $n$-decane) ${ }^{22}$ were selected. As seen from Fig. 8, the alkane solubilities in nitroethane varies from about 0.05 to 0.3 in mole fraction. Similarly, the nitroethane solubilities vary from about 0.35 to 0.05 in $n$-octane and $n$-decane. For 
all the systems, an upper critical solution temperature was observed. While the model can produce an upper critical solution temperature, it will not produce non-classical behavior near the critical region. We have not tested whether the assumed temperature dependence will be reliable with the current formulation. Thus, since the model is limited in its development to non-critical situations, the 2-4 points at the highest temperatures were excluded from the analysis.

In the $n$-alkanes + water systems the $b$-value is near 4000 in three alkanes, but is 5514.3 in $n$-pentane. $b$ parameters obtained for nitroethane are similar (near 6000) in the three shorter alkanes, but not in ndecane. This may be useful to discriminate cases, as we will discuss later. COSMO-SAC predicted negative $c$ parameters for all systems, but the fitted $c$ values had negative signs only in the $\beta$ phase (rich in nitroethane). The contour plots shows that the objective function minimum is located away from $(0,0)$ and most data points are within the $95 \%$ confidence interval (Fig. 8). Independent regression for all six parameters was also conducted for all $n$-alkane systems (Table 7). The nonideality term has more effect than in the hydrocarbon systems and it is slightly more significant than for the aqueous ionic liquids system.

\subsection{Comparison of Unsymmetric model with NRTL}

The performance of the unsymmetric model for LLE correlation can be compared to the NRTL model ${ }^{23}$ on the following form ${ }^{24}$

$$
G^{E}=x_{1} x_{2}\left[\frac{\Delta g_{21} \exp \left(-\alpha \Delta g_{21} / \mathrm{R} T\right)}{x_{1}+x_{2} \exp \left(-\alpha \Delta g_{21} / \mathrm{R} T\right)}+\frac{\Delta g_{12} \exp \left(-\alpha \Delta g_{12} / \mathrm{R} T\right)}{x_{2}+x_{1} \exp \left(-\alpha \Delta g_{12} / \mathrm{R} T\right)}\right]
$$

Sørensen and Arlt ${ }^{1}$ were quite explicit about the inadequacy of the temperature dependence of the NRTL model with temperature independent parameters. In fact, they tabulated different NRTL parameters at different temperatures. Here we will use temperature dependent parameters:

$\Delta \mathrm{g}_{21}=\mathrm{a}_{21}+\mathrm{b}_{21} \mathrm{~T}$ 


$$
\Delta \mathrm{g}_{12}=\mathrm{a}_{12}+\mathrm{b}_{12} \mathrm{~T}
$$

This gives 4 in total: $a_{12}, a_{21}, b_{12}$ and $b_{21}$ in addition to the non-randomness parameter, $\alpha$. The first four are regressed, with $\alpha$ fixed at 0.2. All estimated NRTL parameters are listed in Table 3, and a set of correlation results for water $+[\mathrm{hmim}]\left[\mathrm{BF}_{4}\right], n$-octane + nitroethane and $n$-hexane + water are shown in Fig. 9.

Table 4 compares results obtained with both methods. As can be seen there are cases where the models are very similar in AARD (less than $1.5 \%$ difference), and cases where one or the other model produces the lower value, with a tendency to better overall performance of NRTL. Also, the prediction intervals are similar for the two methods.

We have chosen to seek simplicity in the formulation of the temperature dependence of infinite dilution activity coefficients. Analysis of the infinite dilution expressions of NRTL and the unsymmetric model, show that the NRTL form with temperature dependent parameters has both the zero order and inverse temperature terms that the unsymmetric model has as well as terms with exponential functions. Thus, NRTL has more terms. However, the NRTL form must use the same parameters in both phases, so it is not obvious which model will provide the better fit. At this point NRTL does perform well for most cases investigated.

A deeper analysis if this issue would involve simultaneous incorporation of temperature derivatives, such as partial molar excess enthalpies and heat capacities (at infinite dilution) for the respective phases. The current FST form gives a partial molar heat capacity at infinite dilution of zero, whereas NRTL allows it to be non-zero, though there is no guarantee that the NRTL will be closer to the experimental excess partial molar heat capacity than our value of zero.

One important point of difference between the two models is that, parameters in the unsymmetric model are related to other thermodynamic properties, i.e. their values can be compared to measured data and/or 
be interpreted in terms of quantities that are well-defined molecular physics concepts. For example, $a$ is connected to the partial molar excess entropy at infinite dilution, $b$ to the partial molar excess enthalpy at infinite dilution, and $c$ to the composition derivative of the activity coefficient (connected to correlation function integrals). Parameters in the NRTL model are not explicitly connected to other properties. Thus validation of their values cannot be assessed by comparison with other measured properties.

\section{Discussion}

Models based on theoretical concepts such as molecular thermodynamics allow better determination and justification of parameter values, both for establishing initial values for regression and assessing final values for extension. Further, the expected reliability of such models would allow for implementation in validating measured data.

Here, initial parameter estimates for temperature dependence and dilute solution non-ideality have been made with COSMO-SAC. The estimates have proven to be only qualitatively reliable. Additional databases have been analyzed to examine this situation further.

First, COSMO-SAC calculations of infinite dilution partial molar excess enthalpies were made for 72 binary systems from Sherman et al. ${ }^{25}$ and other literature values ${ }^{26,27}$. The mixtures covered are mostly mixtures of organic species - with and without LLE, including data on water/toluene and nitroalkane/nalkanes. Fig. 10 shows the results where data are in the range from -5 to $25 \mathrm{~kJ} / \mathrm{mol}$. The sign is correct in the majority of cases and only a few of the discrepancies are larger than three $\mathrm{kJ} / \mathrm{mol}$.

FST gives solution non-ideality as a MacLaurin ${ }^{8}$ series in mole fraction. The $c$ parameter is proportional to the infinite dilution derivative of the activity coefficient,

$$
h_{2}^{0 \beta}=\frac{c^{\beta}}{T}=\lim _{x_{1} \rightarrow 0}\left[\frac{\partial \ln \gamma_{1}^{\beta}}{\partial x_{1}}\right]_{T, P}
$$


The behavior of these derivatives has been reported ${ }^{28-32}$. COSMO-SAC can also be evaluated for this property. Note that all values of the derivative must be negative for thermodynamic stability. Table 5 compares predicted COSMO-SAC values with those derived from parameters regressed to VLE with the Wilson equation, NRTL and modified Margules models. The three excess Gibbs energy models were chosen, because descriptions of the derivatives can differ in their reliability ${ }^{28}$. Here, the same negative signs and similar magnitudes demonstrates the variability in fitting VLE data with such models. The differences for the COSMO-SAC model are considerable, though often the sign is correct and some magnitudes are similar. The data in Table 5 are obtained from fits to VLE data, so the derivatives for LLE systems are expected to be much larger than those in Table 5. Thus, while employing COSMO-SAC for selecting initial guesses might be satisfactory, it is unlikely that the method can provide reliable final results.

It would be expected that the parameters in the present model would show systematic variations with molecular structure. In fact, group contribution methods suggest that $b$ values in such systems should be identical ${ }^{33}$. Trends in calorimetric data ${ }^{34,35}$ confirm this expectation. Thus, our regressed $b$ values for water or nitroethane in a series of hydrocarbons should be quite similar. However, within the ranges of uncertainty, the $b$ values are not identical, neither for water nor for nitroethane. If one trusts the result of group contribution analysis that any solute has the same partial molar excess enthalpy in all alkanes, then one conclusion could be that the data sets are inconsistent with this idea and should be suspect. Alternatively, the temperature dependence of the present model could be inadequate to represent the partial molar excess enthalpies of the data. The current form of the model implies that the partial molar excess enthalpy at infinite dilution for any solute/solvent pair is a constant, independent of temperature. Data on partial molar excess enthalpies and partial molar heat capacities at infinite dilution are however not temperature-independent ${ }^{36}$. The impact of these effects requires more studies of accurate data on these properties. 
Table 1 shows that regressed $b$ parameters for water have similar values for solutes in three out of four $n$-alkanes. The COSMO-SAC predictions at $298.15 \mathrm{~K}$ are virtually identical (Table 6 ). On the other hand, for the aqueous ionic liquids, the COSMO SAC predicts negative values, not positive as from regression, indicating that the method can be unreliable.

Reliable models must be developed to validate LLE data, including degree of accuracy, identifying outliers, making connections to other properties, and discerning systematic errors. We have been seeking simplicity in this work, but we have found that the temperature dependence of infinite dilution properties is not in all cases as good as that of NRTL, though it is also not always correct, but a sufficiently reliable temperature dependence has not yet been found. Thus, further studies are needed.

Our form of FST is not directly applicable to multicomponent systems, though rigorous extensions are possible. The form of the application will depend upon the kind of multicomponent system. Multicomponent liquid-liquid systems differ from those of the present manuscript (which essentially deals with temperature variation), since temperature is often unchanging. Again, further data-based study is required.

\section{Conclusions}

A model has been constructed and tested for the correlation of binary LLE data over ranges of temperature. At least four parameters are needed, which is similar to current models. Depending upon the relative solubilities, additional parameters can be needed. A procedure has been given for parameter estimation, including initial guesses from graphical representation of data and from COSMO-SAC estimates, and for uncertainty analysis of the parameters and estimated mole fractions from the regressions. Three types of systems, covering different ranges of solubility and temperature have been examined. 
Comparisons with results from the NRTL model indicate mostly similar reliability within $95 \%$ confidence limits. Comparisons of regressed parameters with estimates from COSMO-SAC show mostly similar temperature dependence, but large discrepancies for solution non-idealities. The model parameter values suggest systematic variations with structure that could be exploited in data validation.

\section{Acknowledgement}

The EU H2020 project "ModLife" (grant agreement no. 675251) is acknowledged.

\section{Author information}

\section{Corresponding Author}

*E-mail: ja@kt.dtu.dk

Notes

The authors declare no competing financial interest. 


\section{List of Figures}

Figure 1. Methodology workflow involved in data correlation.

Figure 2. $\ln x_{i}$ as a function of inverse temperature data for the toluene (1)/ water (2) system ${ }^{13}$.

Figure 3a. Contour map of objective function with varying values of $c^{\alpha}$ and $c^{\beta}$ parameters for toluene (1)/water (2). Ranges of both $c$ parameters are provided by COSMO-SAC (green square). Red dot indicates minimum of objective function.

Figure 3b. Zoom on contour map of objective function with varying values of $c^{\alpha}$ and $c^{\beta}$ parameters for toluene (1)/water (2). Red dot indicates minimum of objective function.

Figure 3c. Further zoom on contour map of objective function with varying values of $c^{\alpha}$ and $c^{\beta}$ parameters for toluene (1) with water (2). Red dot indicates the minimum of objective function.

Figure 4. Liquid-liquid equilibria in toluene (1) with water (2); results of uncertainty analysis. Note the confidence intervals are similar in both phases, but scaling of the axes is different. The error bars show experimental uncertainty in the molar fraction.

Figure 5. Liquid-liquid equilibrium in hexane (1) with water (2) including uncertainty analysis.

Figure 6. Liquid-liquid equilibrium in $[\mathrm{hmim}]\left[\mathrm{BF}_{4}\right](1)$ with water (2) including uncertainty analysis.

Figure 7. Contour plots for $[\mathrm{hmim}]\left[\mathrm{BF}_{4}\right]$ with water; red point indicates minimum of the objective function; green square - COSMO-SAC prediction. a) Full range of $c$ provided by COSMO-SAC model, b) zoom for smaller range.

Figure 8. Liquid-liquid equilibrium of hydrocarbon (1)/nitroethane (2) systems including uncertainty analysis; a) $n$ - octane, b) n-decane.

Figure 9. Sample of liquid-liquid equilibrium correlation by unsymmetric model (with confidence intervals) and NRTL in the systems $[\mathrm{hmim}]\left[\mathrm{BF}_{4}\right](1) /$ water (2) (top), octane (1)/nitroethane (2) (middle) and hexane (1)/water (2) (bottom).

Figure 10. Partial molar excess enthalpies at infinite dilution of 72 binary systems at $298.15 \mathrm{~K}$ determined experimentally and predicted by the COSMO-SAC model. Root mean square deviation from $R M S D=\left[\frac{1}{N} \sum_{i=1}^{N}\left(\overline{h_{\text {calc }}^{E, \infty}}-\overline{h_{\text {exp }}^{E, \infty}}\right)^{2}\right]^{1 / 2}$ is equal to $2.6 \mathrm{~kJ} / \mathrm{mol}$. Full circles represent results for nitromethane/nitroethane and hydrocarbons (including $n$-alkanes) systems, full square corresponds to the toluene/water system. 


\section{LLE experimental data:}

Compositions in both phases as a function of temperature

$$
x_{1}^{\alpha}, x_{1}^{\beta}, T
$$

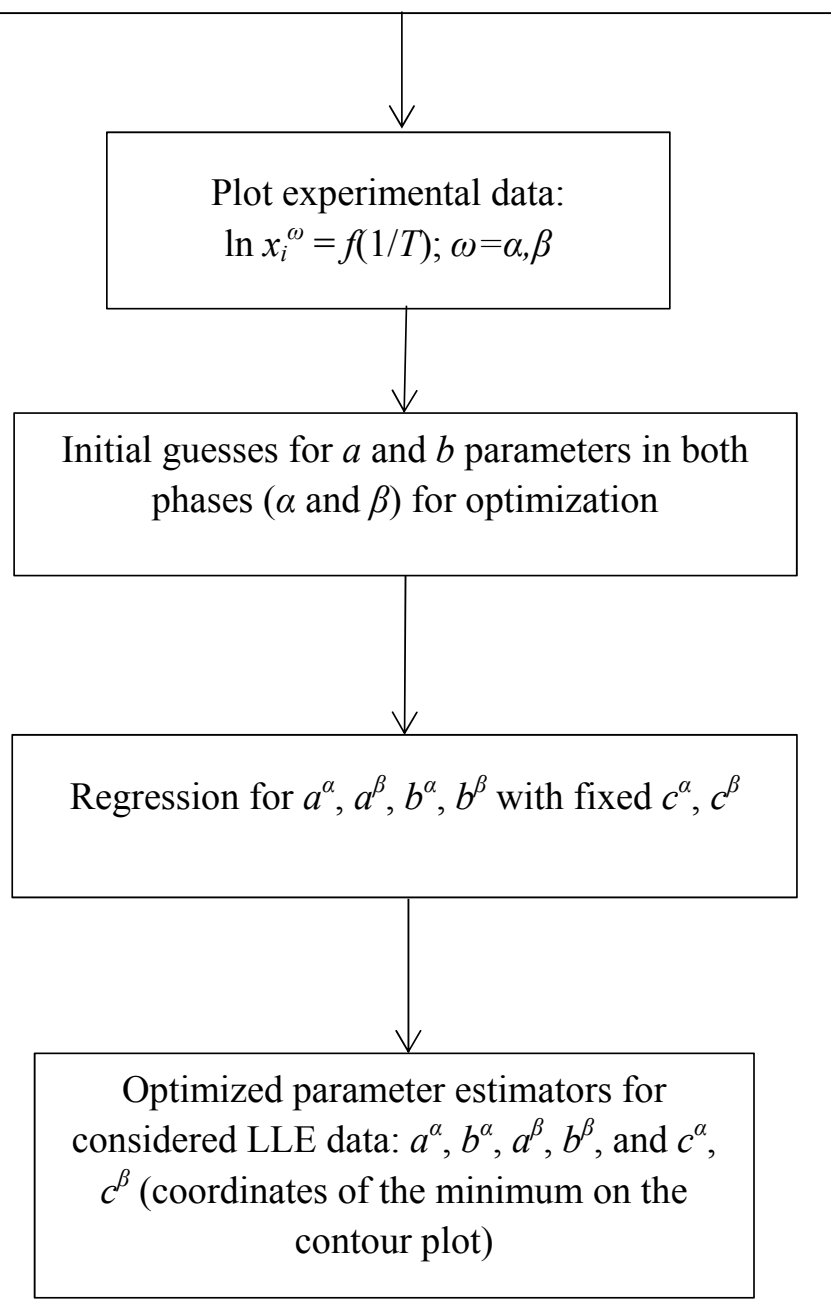

Figure 1. Methodology workflow involved in data correlation. 

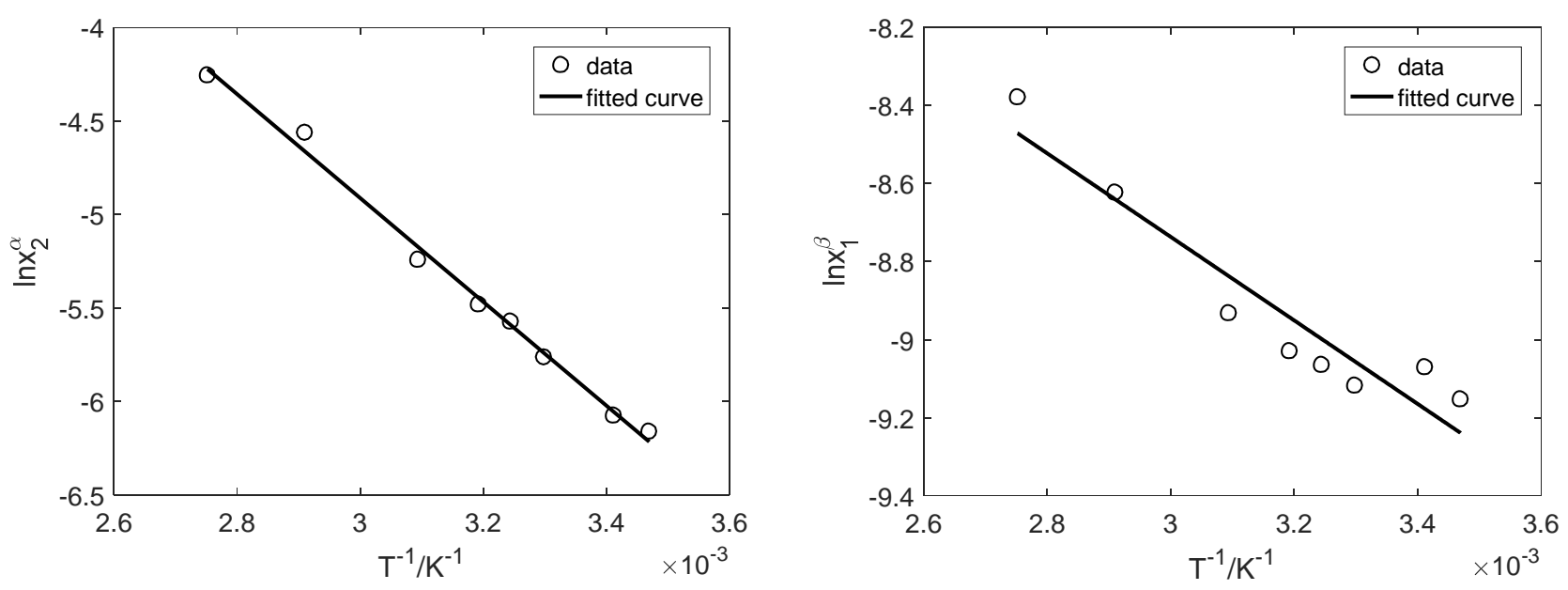

Figure 2. $\ln x_{i}$ as a function of inverse temperature data for the toluene (1)/ water (2) system ${ }^{13}$.

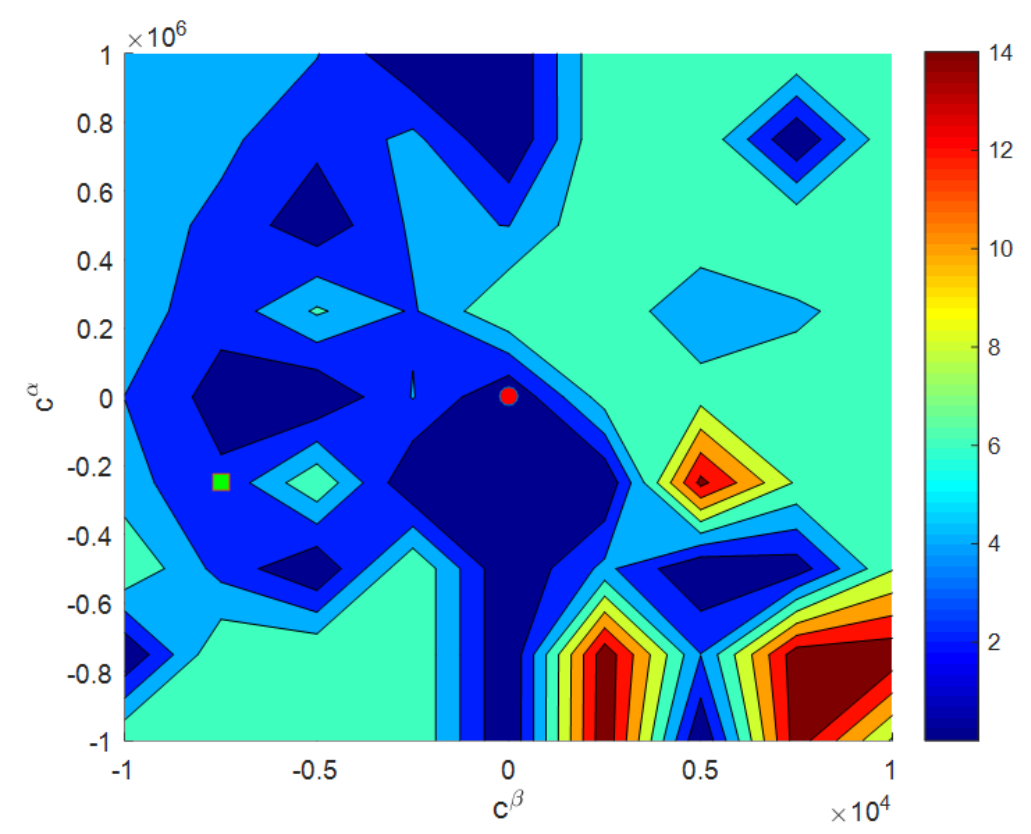

Figure 3a. Contour map of objective function with varying values of $c^{\alpha}$ and $c^{\beta}$ parameters for toluene (1)/water (2). Ranges of both $c$ parameters are provided by COSMO-SAC (green square). Red dot indicates minimum of objective function. 


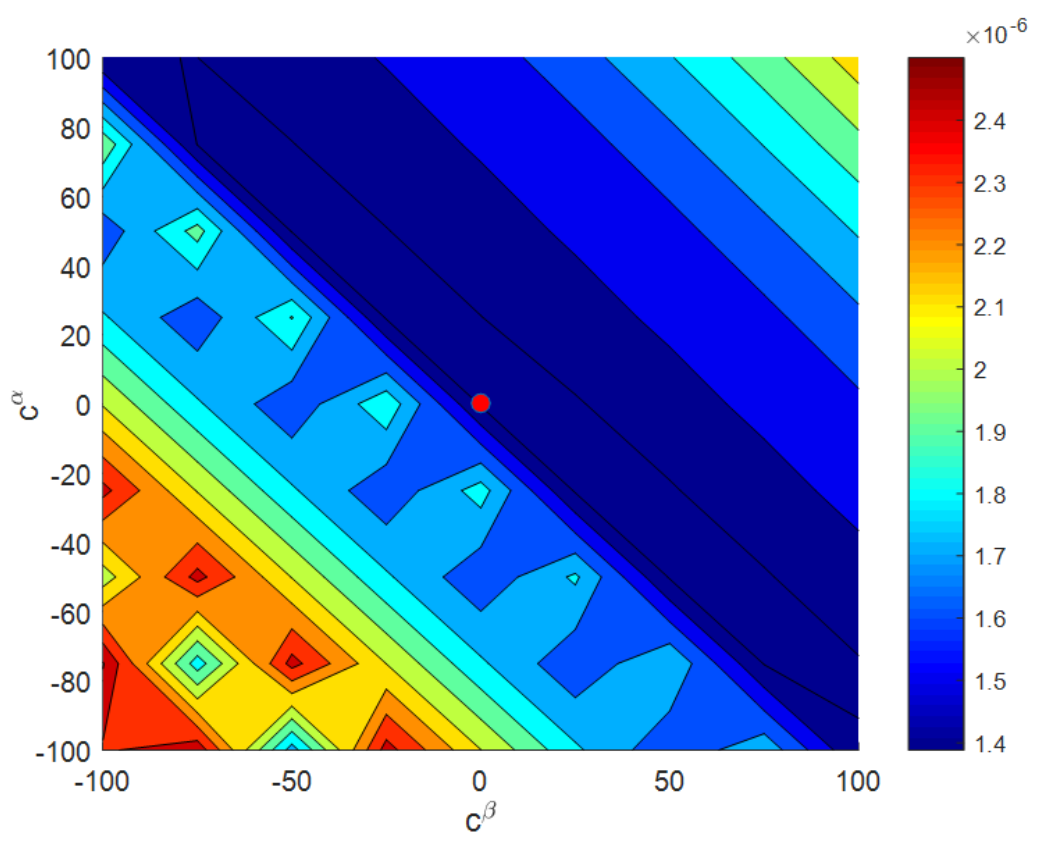

Figure 3b. Zoom on contour map of objective function with varying values of $c^{\alpha}$ and $c^{\beta}$ parameters for toluene (1)/water (2). Red dot indicates minimum of objective function.

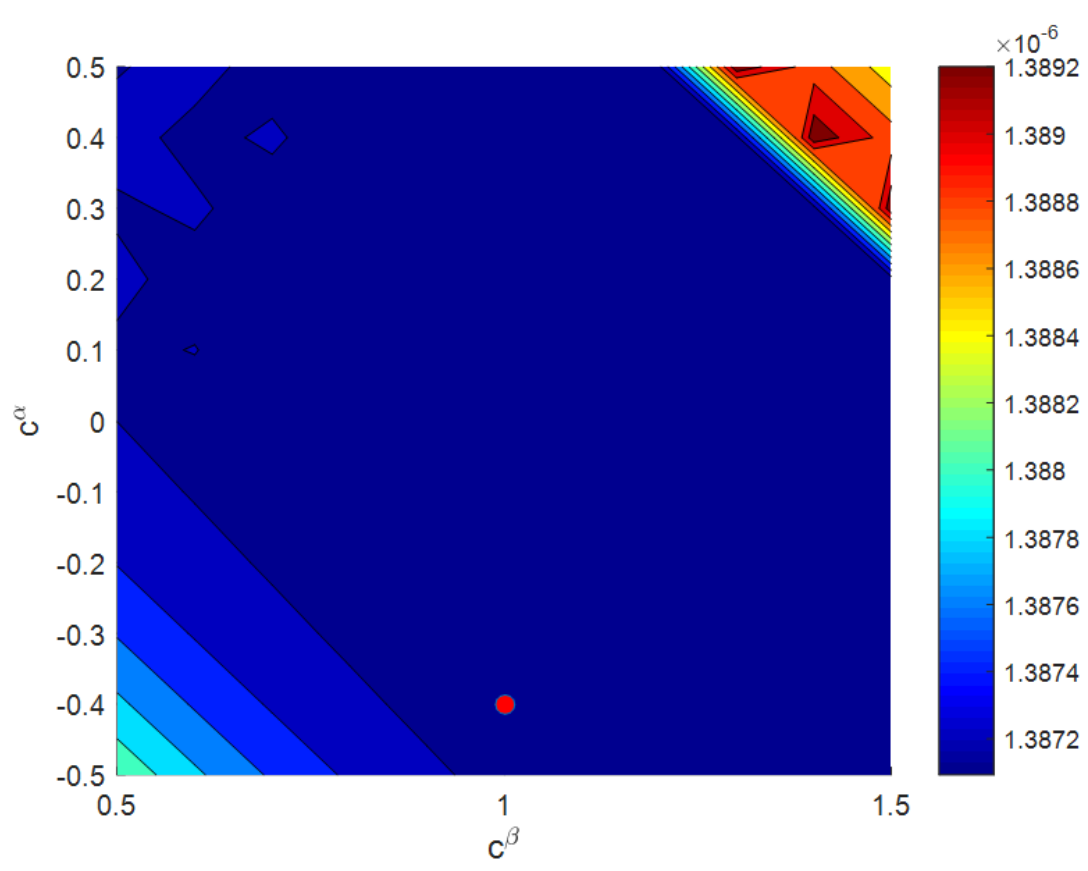

Figure 3c. Further zoom on contour map of objective function with varying values of $c^{\alpha}$ and $c^{\beta}$ parameters for toluene (1) with water (2). Red dot indicates the minimum of objective function. 


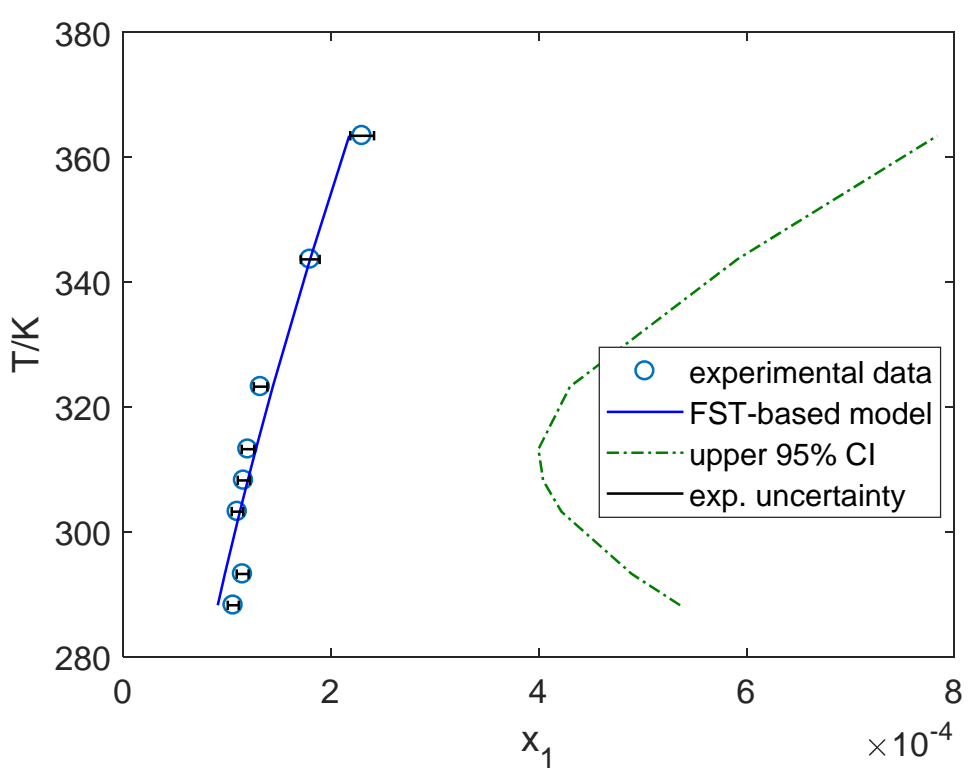

(a)

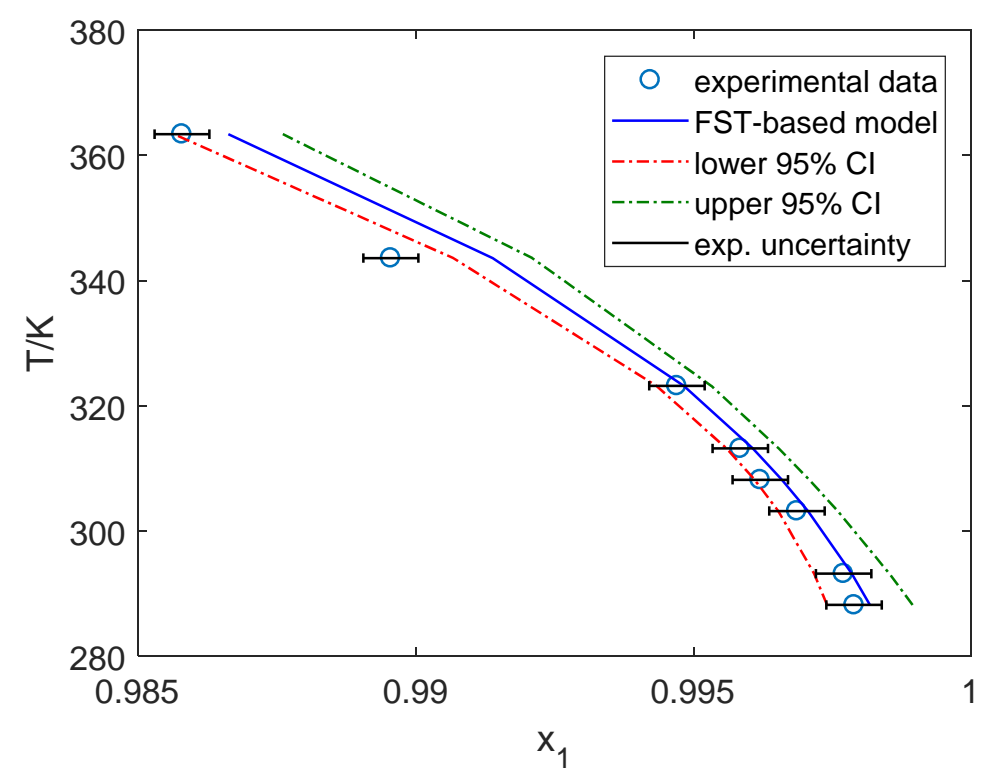

(b)

Figure 4. Liquid-liquid equilibria in toluene (1) with water (2); results of uncertainty analysis. Note the confidence intervals are similar in both phases, but scaling of the axes is different. The error bars show experimental uncertainty in the molar fraction. 


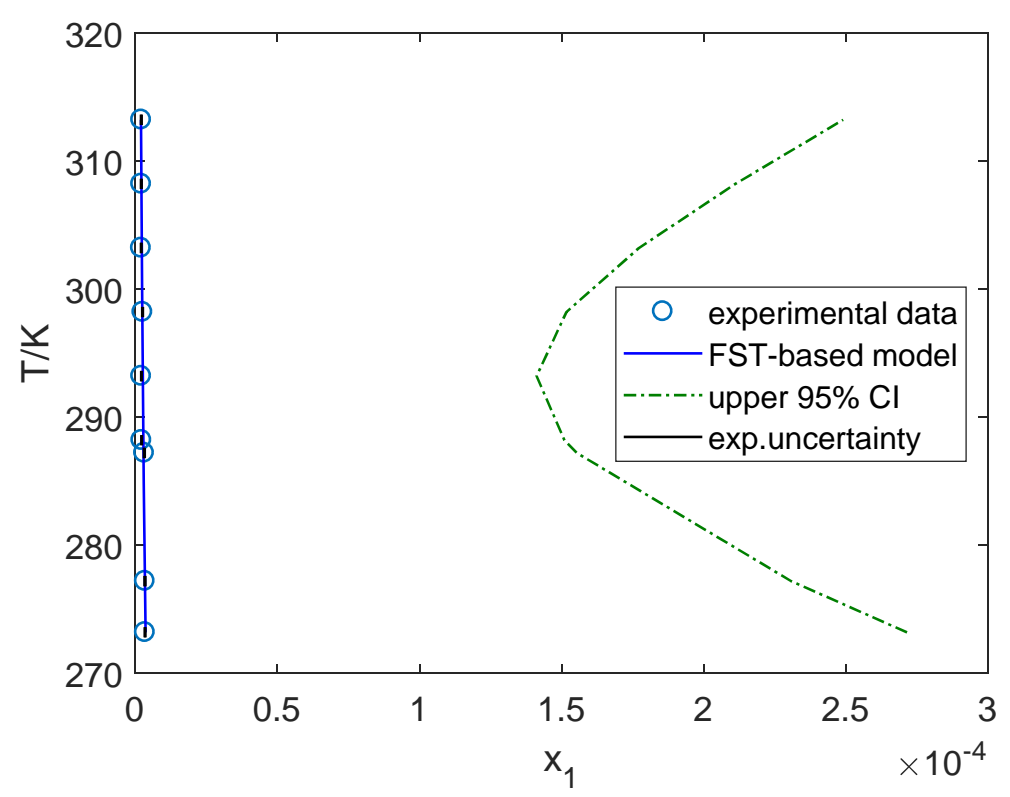

(a)

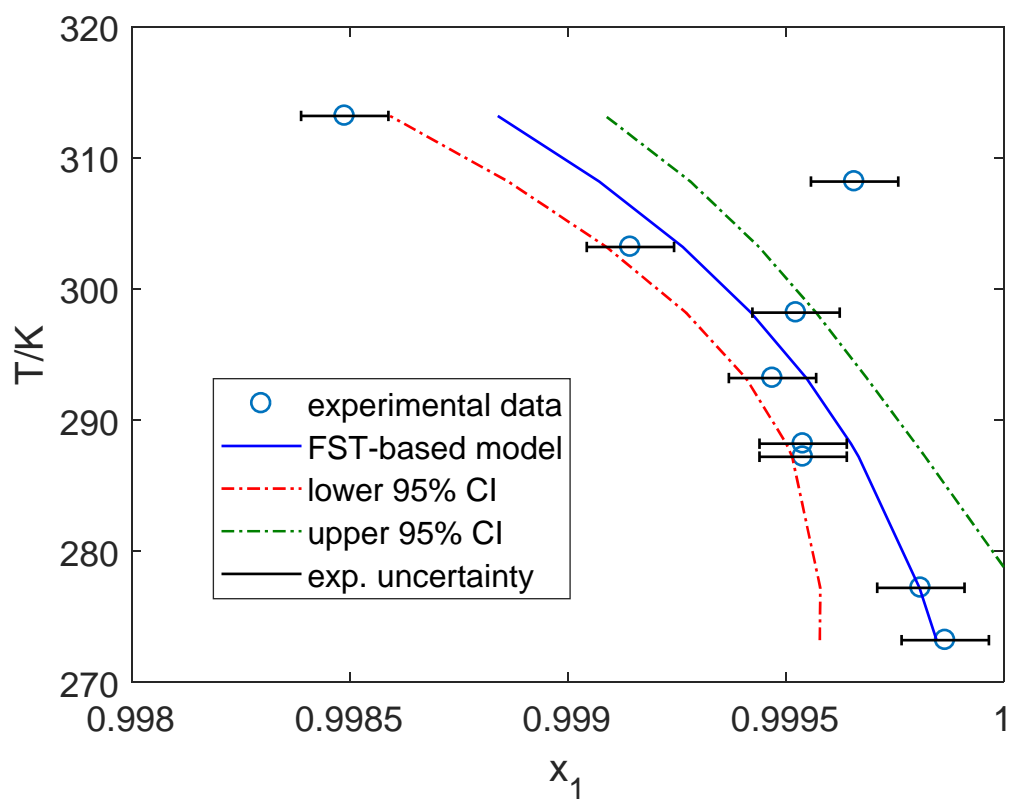

(b)

Figure 5. Liquid-liquid equilibrium in $n$-hexane (1) with water (2) including uncertainty analysis. 


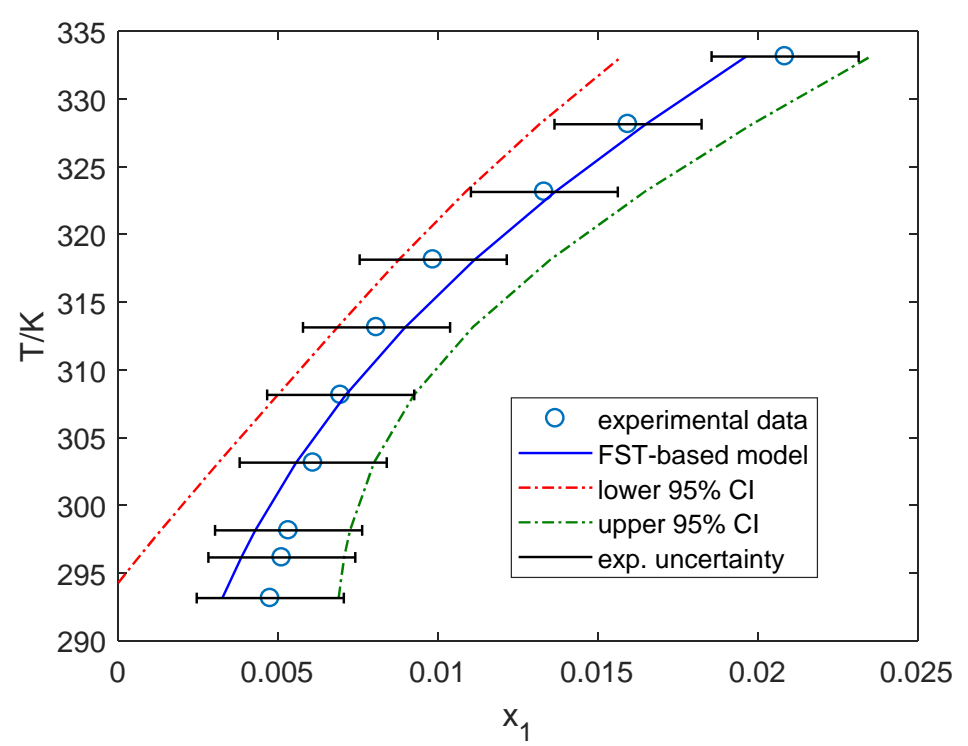

(a)

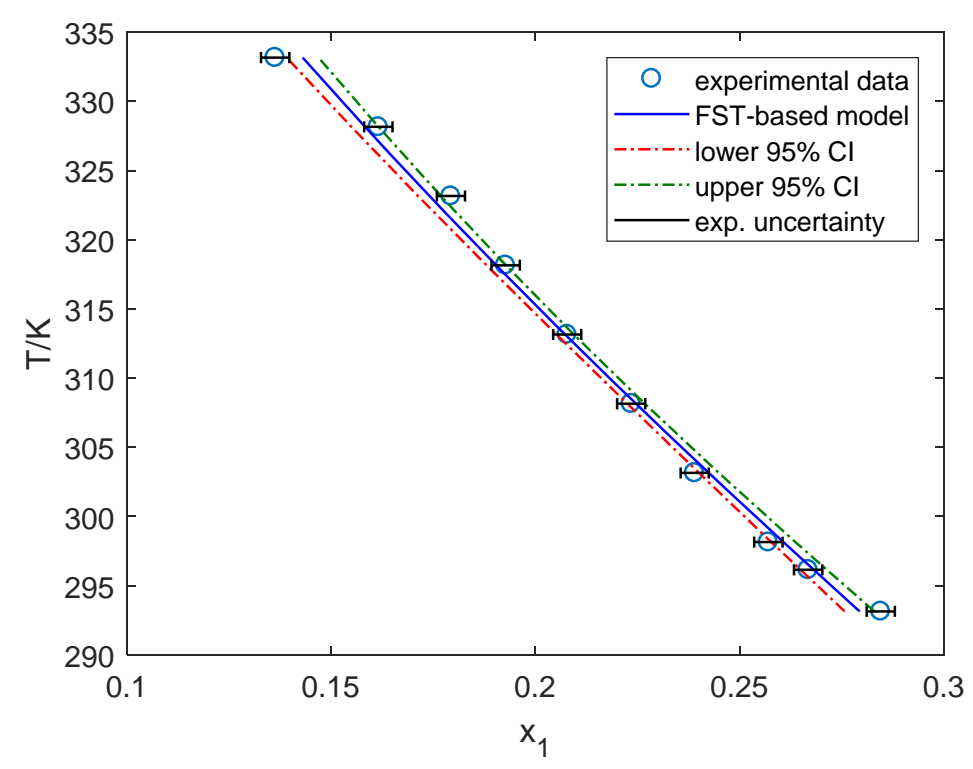

(b)

Figure 6. Liquid-liquid equilibrium in $[\mathrm{hmim}]\left[\mathrm{BF}_{4}\right](1)$ with water (2) including uncertainty analysis. 


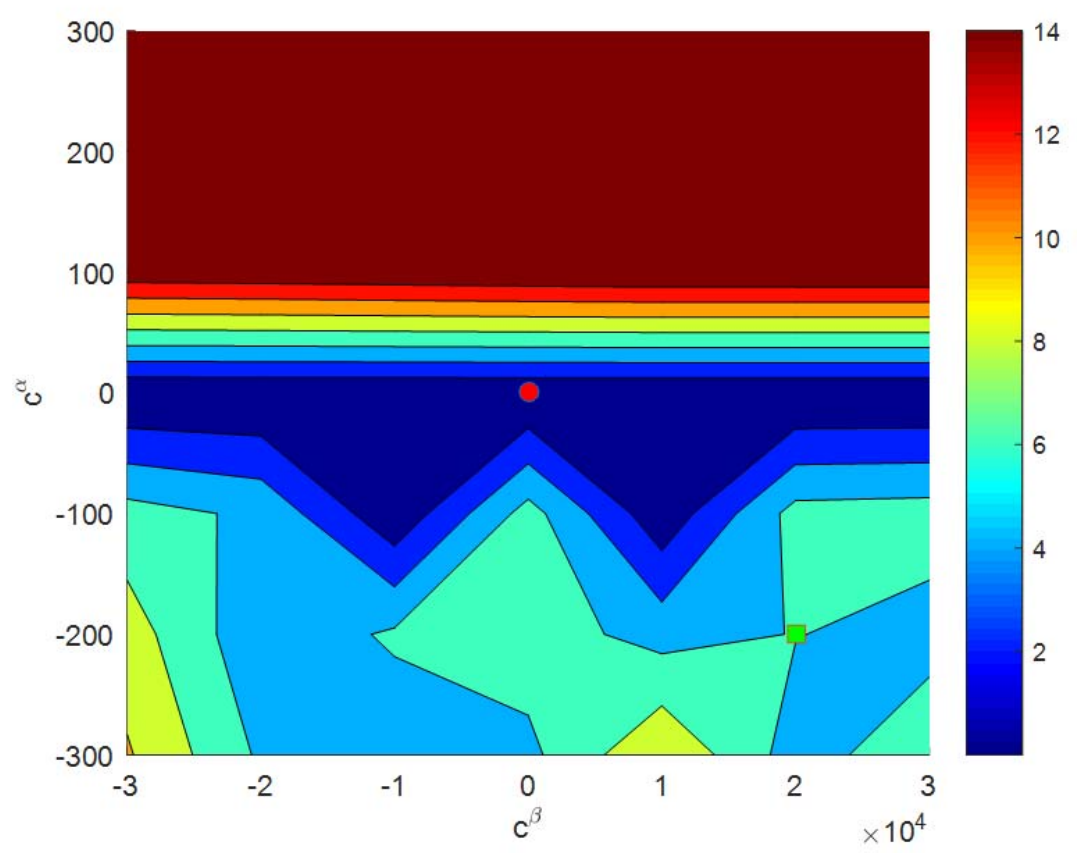

(a)

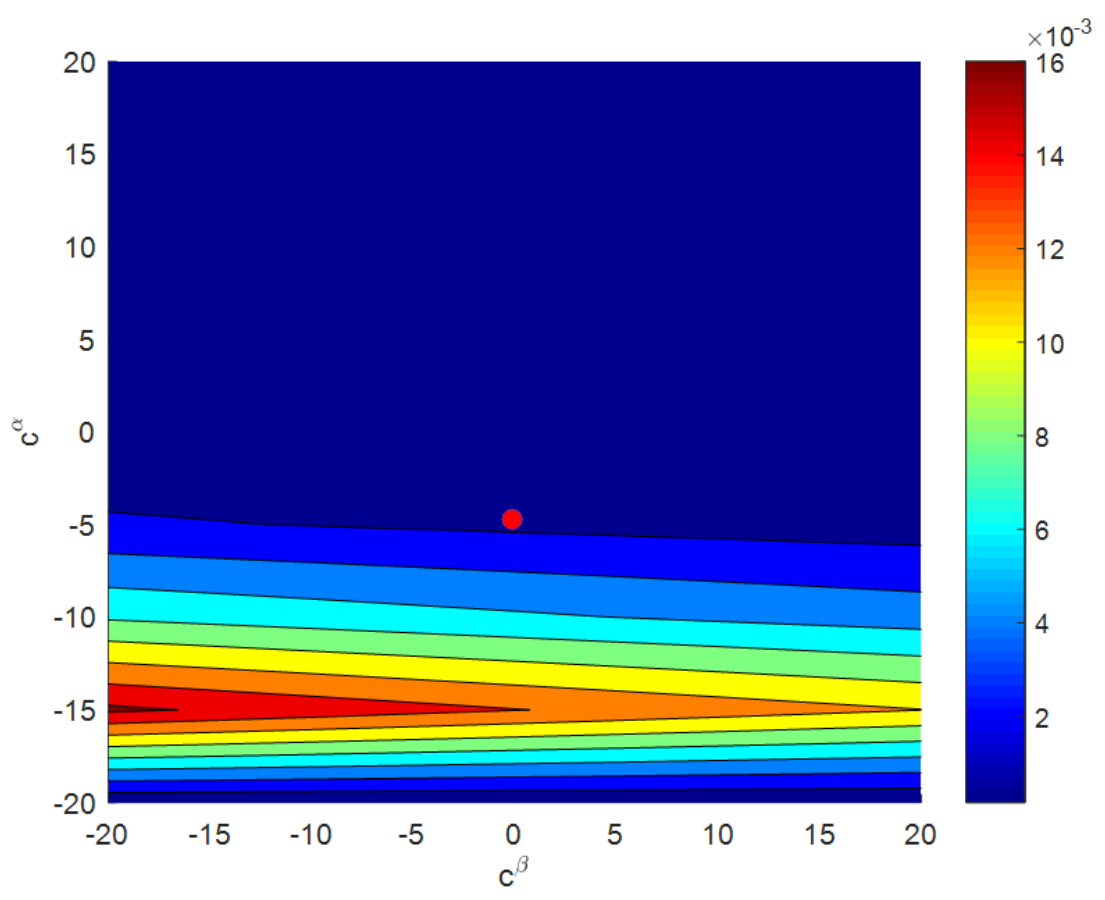

(b)

Figure 7. Contour plots for $[\mathrm{hmim}]\left[\mathrm{BF}_{4}\right]$ with water; red point indicates minimum of the objective function; green square - COSMO-SAC prediction. a) Full range of $c$ provided by COSMO-SAC model, b) zoom for smaller range 

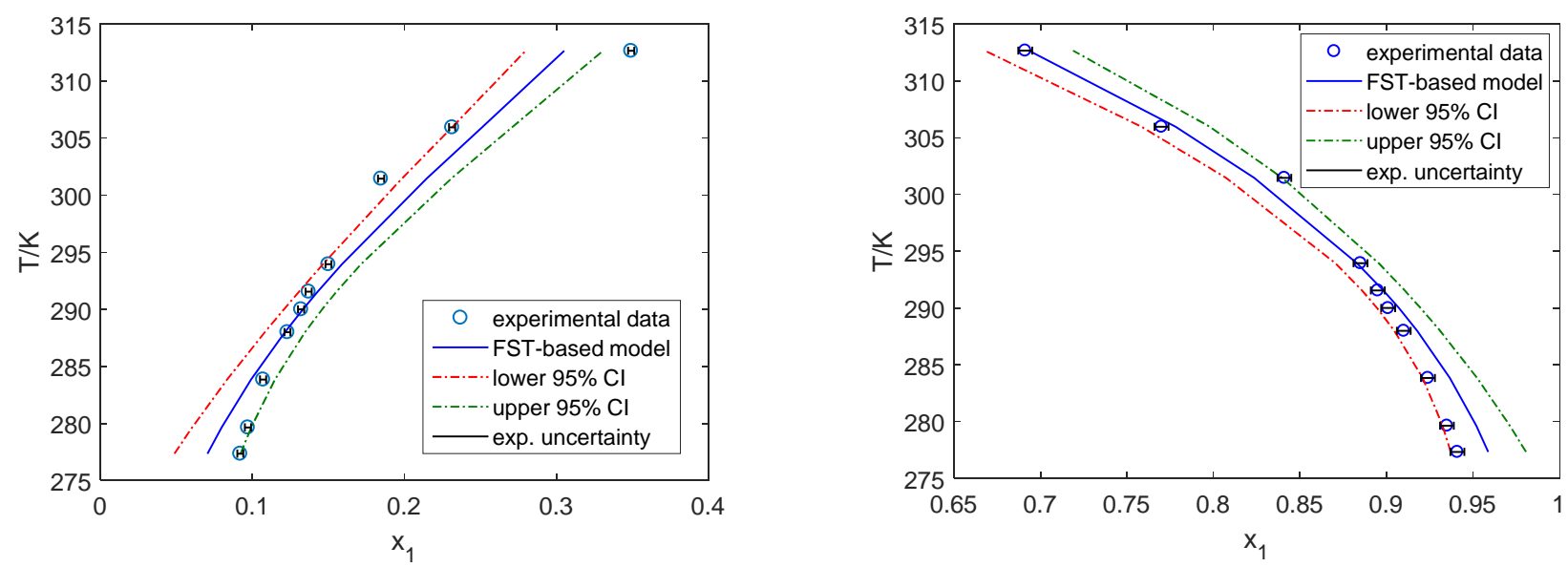

(a)
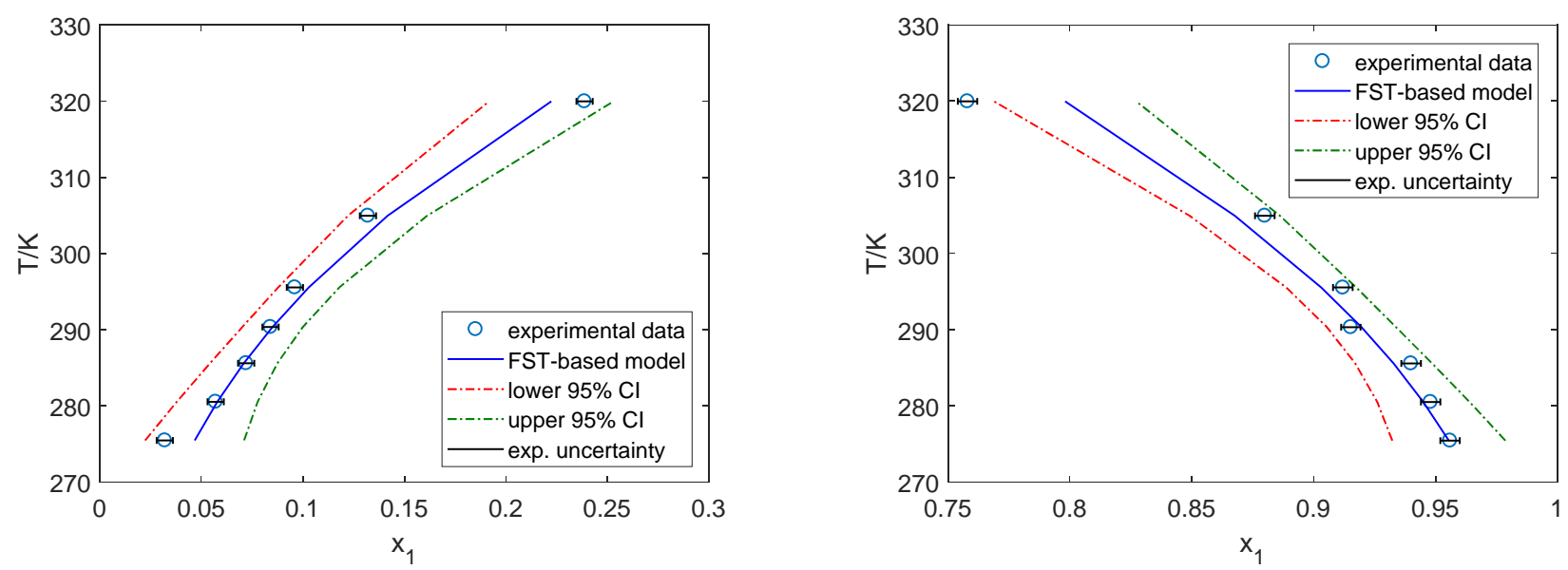

(b)

Figure 8. Liquid-liquid equilibrium of hydrocarbon (1)/nitroethane (2) systems including uncertainty analysis; a) $n$ - octane, b) $n$-decane. 

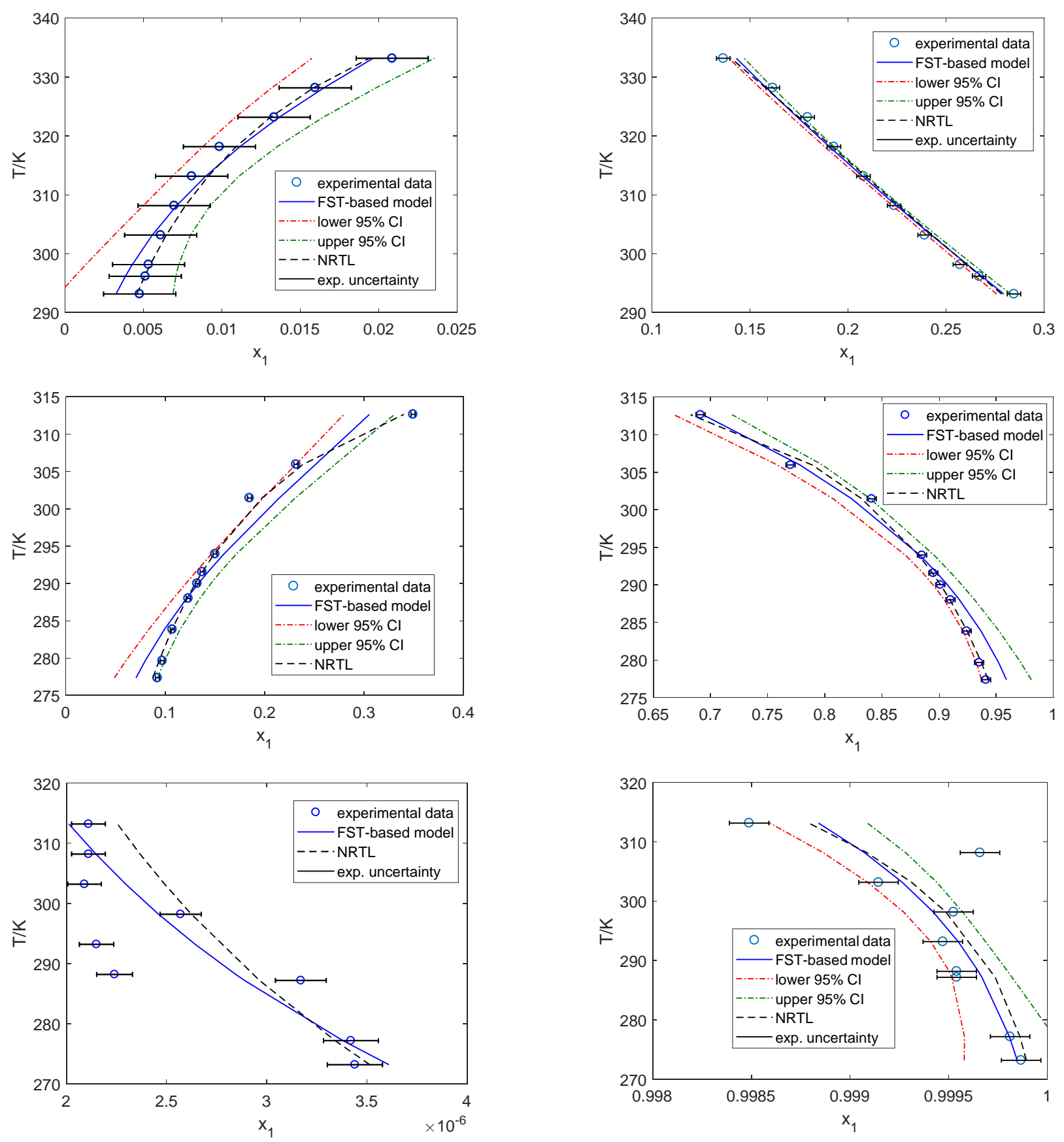

Figure 9. Sample of liquid-liquid equilibrium correlation by unsymmetric model (with confidence intervals) and NRTL in the systems $[\mathrm{hmim}]\left[\mathrm{BF}_{4}\right](1) /$ water (2) (top), octane (1)/nitroethane (2) (middle) and hexane (1)/water (2) (bottom). The error bars show experimental uncertainty in the mole fraction. 


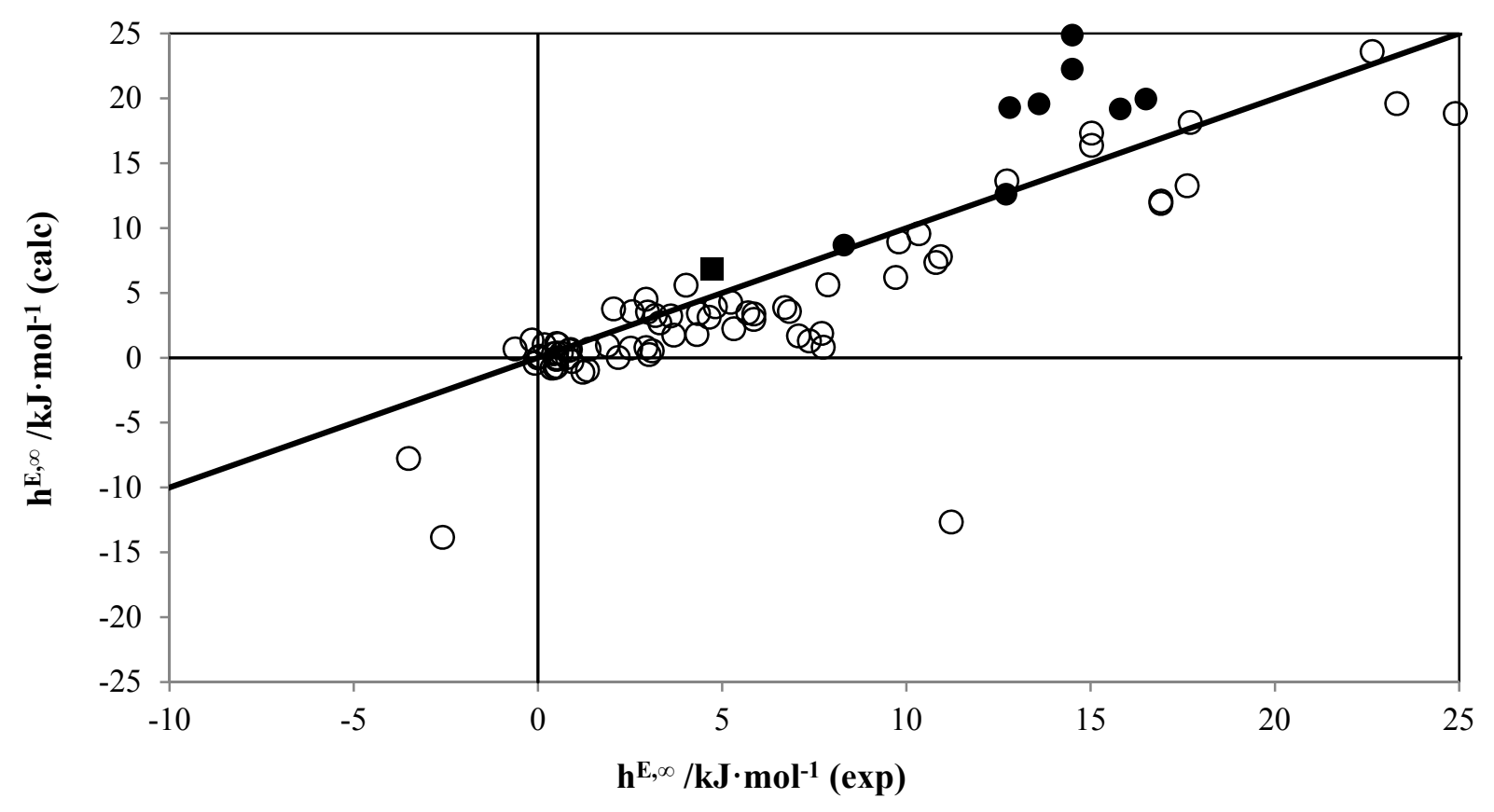

Figure 10. Partial molar excess enthalpies at infinite dilution of 72 binary systems at $298.15 \mathrm{~K}$ determined experimentally and predicted by the COSMO-SAC model. Root mean square deviation from $R M S D=\left[\frac{1}{N} \sum_{i=1}^{N}\left(\overline{h_{\text {calc }}^{E, \infty}}-\overline{h_{\text {exp }}^{E, \infty}}\right)^{2}\right]^{1 / 2}$ is equal to $2.6 \mathrm{~kJ} / \mathrm{mol}$. Full circles represent results for nitromethane/nitroethane and hydrocarbons (including $n$-alkanes) systems, full square corresponds to the toluene/water system. 


\section{List of Tables}

Table 1. Estimated parameters for all considered systems. In all tables phase $\alpha$ is rich in component 1 and $\beta$ rich in component 2.

Table 2. Sample of parameter initial guesses and optimized values (in parentheses).

Table 3. Estimated parameters for NRTL $(\alpha=0.2)$ for all considered systems.

Table 4. Comparison of average absolute relative deviation (AARD) in mole fraction using unsymmetric formulation and NRTL.

Table 5. Activity coefficient derivatives with respect to composition with different models: COSMO-SAC, NRTL, Modified Margules and Wilson equation.

Table 6. Comparison of parameter values estimated with COSMO-SAC and regressed values.

Table 7. Regressed parameters (all six) for considered systems. Parameter values with confidence ranges from eq. (26). In all cases phase $\alpha$ is rich in component 1 and $\beta$ rich in component 2. 
Table 1. Estimated parameters for all considered systems. In all tables phase $\alpha$ is rich in component 1 and $\beta$ rich in component 2.

\begin{tabular}{|c|c|c|c|c|c|c|}
\hline System (1)/(2) & $a^{\alpha}$ & $b^{\alpha} \dagger$ & $a^{\beta}$ & $b^{\beta}$ & $c^{\alpha}$ & $c^{\beta}$ \\
\hline toluene/water & $-3.340 \pm 0.002$ & $2784.8 \pm 0.5$ & $5.028 \pm 0.002$ & $1079.9 \pm 0.5$ & -0.4 & (1) \\
\hline$n$-pentane/water & $-10.82 \pm 0.0002$ & $5514.3 \pm 0.1$ & $15.3082 \pm 0.0002$ & $-1152 \pm 0.1$ & 0 & 0 \\
\hline$n$-hexane/water & $-7.040 \pm 0.002$ & $4322.3 \pm 0.4$ & $17.144 \pm 0.002$ & $-1248.8 \pm 0.4$ & $(0.1)$ & -0.05 \\
\hline$n$-heptane/water & $-4.7643 \pm 0.0023$ & $3592.8 \pm 0.7$ & $17.100 \pm 0.0023$ & $-786.27 \pm 0.69$ & 0 & 0 \\
\hline$n$-octane/water & $-5.149 \pm 0.001$ & $3737 \pm 0.3$ & $22.95 \pm 0.001$ & $-2032 \pm 0.3$ & 0 & 0 \\
\hline$[\mathrm{hmim}]\left[\mathrm{BF}_{4}\right] /$ water & $-1.241 \pm 0.023$ & $463.1 \pm 7.1$ & $-14.55 \pm 0.02$ & $5525.9 \pm 7.1$ & -4.7 & -0.1 \\
\hline$[\mathrm{omim}]\left[\mathrm{BF}_{4}\right] /$ water & $-1.258 \pm 0.030$ & $501.1 \pm 7.4$ & $-11.15 \pm 0.03$ & $4717.7 \pm 7.4$ & -11.3 & 0 \\
\hline$n$-hexane/nitroethane & $-19.553 \pm 0.177$ & $6140 \pm 51.9$ & $-18.939 \pm 0.177$ & $5931.7 \pm 51.9$ & (2.5) & -8.2 \\
\hline$n$-octane/ nitroethane & $-17.039 \pm 0.159$ & $5577.6 \pm 46.4$ & $-13.799 \pm 0.159$ & $4561.2 \pm 46.4$ & (60) & -40 \\
\hline $\begin{array}{l}\text { 2,2,4-trimethylpentane/ } \\
\text { nitroethane }\end{array}$ & $-18.659 \pm 0.206$ & $5895.8 \pm 59.9$ & $-12.501 \pm 0.206$ & $4020.9 \pm 59.9$ & (10) & -5 \\
\hline$n$-decane/ nitroethane & $-8.489 \pm 0.141$ & $3152.3 \pm 41.3$ & $-9.486 \pm 0.141$ & $3444.1 \pm 41.3$ & (11) & -8 \\
\hline
\end{tabular}

$\dagger$ Numbers in rectangles are expected to be similar for water in $n$-alkanes and nitroethane in alkanes. 
Table 2. Sample of parameter initial guesses and optimized values (in parentheses).

\begin{tabular}{|c|c|c|c|c|}
\hline System (1)/(2) & $a^{\alpha}$ & $b^{\alpha}$ & $a^{\beta}$ & $b^{\beta}$ \\
\hline toluene/water & $-3.415(-3.340)$ & $2775.9(2784.8)$ & $5.530(5.028)$ & $1068.8(1079.9)$ \\
\hline$n$-hexane/water & $-5.248(-7.040)$ & $3802.7(4322.3)$ & $16.888(17.144)$ & $-1172.7(-1248.8)$ \\
\hline$[$ omim $]\left[\mathrm{BF}_{4}\right]$ / water & $-1.348(-1.258)$ & $481.66(501.1)$ & $-18.939(-11.15)$ & $4027.5(4717.2)$ \\
\hline$n$-hexane/nitroethane & $-13.602(-19.553)$ & $4467.9(6140)$ & $-13.462(-18.939)$ & $4392.0(5931.7)$ \\
\hline
\end{tabular}

Table 3. Estimated parameters for NRTL model $(\alpha=0.2)$ for all considered systems.

\begin{tabular}{|c|c|c|c|c|}
\hline System (1) / (2) & $a_{12} / \mathrm{J} \cdot \mathrm{mol}^{-1}$ & $a_{21} / \mathrm{J} \cdot \mathrm{mol}^{-1}$ & $b_{12} / \mathrm{J} \cdot \mathrm{K}^{-1} \cdot \mathrm{mol}^{-1}$ & $b_{21} / \mathrm{J} \cdot \mathrm{K}^{-1} \cdot \mathrm{mol}^{-1}$ \\
\hline toluene / water & $\begin{array}{c}21722.3 \\
( \pm 2973.1)\end{array}$ & $\begin{array}{c}3310.97 \\
( \pm 279.71)\end{array}$ & $\begin{array}{l}-37.855 \\
( \pm 9.125)\end{array}$ & $\begin{array}{c}48.697 \\
( \pm 8.637)\end{array}$ \\
\hline$n$-pentane / water & $\begin{array}{c}44538.7 \\
( \pm 8192.0)\end{array}$ & $\begin{array}{l}-6039.78 \\
( \pm 538.99)\end{array}$ & $\begin{array}{c}-97.015 \\
( \pm 28.437)\end{array}$ & $\begin{array}{c}100.704 \\
( \pm 18.872)\end{array}$ \\
\hline$n$-hexane / water & $\begin{array}{c}34877.8 \\
( \pm 4546.74)\end{array}$ & $\begin{array}{c}-4092.98 \\
( \pm 1402.39)\end{array}$ & $\begin{array}{c}-65.676 \\
( \pm 26.718)\end{array}$ & $\begin{array}{l}106.811 \\
( \pm 7.305)\end{array}$ \\
\hline$n$-heptane / water & $\begin{array}{c}28728.9 \\
( \pm 12298.7)\end{array}$ & $\begin{array}{l}-2496.62 \\
( \pm 989.89)\end{array}$ & $\begin{array}{c}-46.250 \\
( \pm 40.420)\end{array}$ & $\begin{array}{l}113.682) \\
( \pm 32.518\end{array}$ \\
\hline$n$-octane / water & $\begin{array}{c}35820.5 \\
( \pm 1680.6)\end{array}$ & $\begin{array}{l}-3024.11 \\
( \pm 513.86)\end{array}$ & $\begin{array}{c}-65.323 \\
( \pm 97.900)\end{array}$ & $\begin{array}{c}129.695 \\
( \pm 29.933)\end{array}$ \\
\hline$[\mathrm{hmim}]\left[\mathrm{BF}_{4}\right]$ / water & $\begin{array}{c}12629.1 \\
( \pm 1026.4)\end{array}$ & $\begin{array}{l}4517.63 \\
( \pm 386.8)\end{array}$ & $\begin{array}{l}-63.499 \\
( \pm 3.329)\end{array}$ & $\begin{array}{c}49.864 \\
( \pm 1.197)\end{array}$ \\
\hline$[$ omim $]\left[\mathrm{BF}_{4}\right] /$ water & $\begin{array}{c}14934.6 \\
( \pm 1057.5)\end{array}$ & $\begin{array}{l}16316.3 \\
( \pm 335.6)\end{array}$ & $\begin{array}{l}-70.318 \\
( \pm 3.726)\end{array}$ & $\begin{array}{c}17.289 \\
( \pm 0.939)\end{array}$ \\
\hline$n$-hexane / nitroethane & $\begin{array}{c}13244.9 \\
( \pm 2858.1)\end{array}$ & $\begin{array}{c}15499.6 \\
( \pm 2665.9)\end{array}$ & $\begin{array}{l}-32.908 \\
( \pm 9.639)\end{array}$ & $\begin{array}{l}-42.699 \\
( \pm 8.995)\end{array}$ \\
\hline$n$-octane / nitroethane & $\begin{array}{c}17549.8 \\
( \pm 1483.4)\end{array}$ & $\begin{array}{c}7345.34 \\
( \pm 1323.8)\end{array}$ & $\begin{array}{l}-45.489 \\
( \pm 4.935)\end{array}$ & $\begin{array}{l}-14.240 \\
( \pm 4.429)\end{array}$ \\
\hline 2,2,4-trimethylpentane/ nitroethane & $\begin{array}{c}20568.4 \\
( \pm 2722.9)\end{array}$ & $\begin{array}{c}5002.12 \\
( \pm 222.03)\end{array}$ & $\begin{array}{l}-56.436 \\
( \pm 9.217)\end{array}$ & $\begin{array}{c}-7.2483 \\
( \pm 0.7545)\end{array}$ \\
\hline$n$-decane / nitroethane & $\begin{array}{l}13568.6 \\
( \pm 212.8)\end{array}$ & $\begin{array}{c}13295.9 \\
( \pm 2051.6)\end{array}$ & $\begin{array}{l}-31.446 \\
( \pm 6.939\end{array}$ & $\begin{array}{l}-31.356 \\
( \pm 6.700\end{array}$ \\
\hline
\end{tabular}


Table 4. Comparison of average absolute relative deviation (AARD) in mole fraction using unsymmetric formulation and NRTL.

\begin{tabular}{lcc}
\hline System (1)/(2) & AARD*/\% & NRTL \\
\hline toluene / water & Unsymmetric model & 5.71 \\
$n$-pentane / water & 4.19 & 3.83 \\
$n$-hexane / water & 3.98 & 2.97 \\
$n$-heptane / water & 4.60 & 6.66 \\
$n$-octane / water & 6.97 & 1.9 \\
& 8.48 & 3.54 \\
{$[\mathrm{hmim}]\left[\mathrm{BF}_{4}\right]$ / water } & 7.00 & 24.49 \\
& & \\
{$\left[\right.$ omim] $\left[\mathrm{BF}_{4}\right]$ / water } & 22.69 & 2.97 \\
$n$-hexane / nitroethane & & 1.51 \\
& 4.31 & 0.84 \\
$n$-octane / nitroethane & & 5.25 \\
2,2,4-trimethylpentane / nitroethane & 5.43 & \\
$n$-decane / nitroethane & 3.37 & 5.99 \\
\hline
\end{tabular}

$$
{ }^{*} \mathrm{AARD}=\frac{100}{N} \sum_{i=1}^{N}\left|\frac{x_{i}^{\text {calc }}-x_{i}^{e x p}}{x_{i}^{\text {exp }}}\right|
$$


Table 5. Activity coefficient derivatives with respect to composition with different models: COSMO-SAC, NRTL, Modified Margules and Wilson equation.

\begin{tabular}{|c|c|c|c|c|c|c|c|c|c|}
\hline \multirow{2}{*}{ System (1)/(2) } & \multirow[b]{2}{*}{$T / \mathrm{K}$} & \multicolumn{2}{|c|}{ COSMO-SAC } & \multicolumn{2}{|c|}{ NRTL } & \multicolumn{2}{|c|}{ Mod Margules } & \multicolumn{2}{|c|}{ Wilson } \\
\hline & & $\mathrm{d} \ln \gamma_{1} / \mathrm{d} x_{1}$ & $\mathrm{~d} \ln \gamma_{2} / \mathrm{d} x_{2}$ & $\mathrm{~d} \ln \gamma_{1} / \mathrm{d} x_{1}$ & $\mathrm{~d} \ln \gamma_{2} / \mathrm{d} x_{2}$ & $\mathrm{~d} \ln \gamma_{1} / \mathrm{d} x_{1}$ & $\mathrm{~d} \ln \gamma_{2} / \mathrm{d} x_{2}$ & $\mathrm{~d} \ln \gamma_{1} / \mathrm{d} x_{1}$ & $\mathrm{~d} \ln \gamma_{2} / \mathrm{d} x_{2}$ \\
\hline \multicolumn{10}{|c|}{$x_{1}=0$} \\
\hline $\begin{array}{l}\text { benzene / aniline } \\
\text { methanol / water } \\
\text { acetone / benzene } \\
\text { acetone / water } \\
\text { ethanol / benzene } \\
\text { 1-propanol / water } \\
\text { aniline / toluene } \\
\mathrm{CCl}_{4} \text { / methanol } \\
\mathrm{CCl}_{4} \text { / ethanol } \\
\mathrm{CCl}_{4} \text { / acetone } \\
\mathrm{CCl}_{4} \text { / aniline }\end{array}$ & $\begin{array}{l}298.15 \\
313.05 \\
298.15 \\
298.15 \\
298.15 \\
303.15 \\
293.15 \\
293.15 \\
293.15 \\
313.15 \\
298.15\end{array}$ & $\begin{array}{l}-1.09 \\
-4.23 \\
-0.183 \\
-8.89 \\
-318 \\
-20.1 \\
-2.17 \\
-4.13 \\
-1.79 \\
-0.385 \\
-3.19\end{array}$ & & $\begin{array}{l}-0.694 \\
-2.01 \\
-1.32 \\
-6.01 \\
-14.1 \\
-17.1 \\
-9.36 \\
-6.55 \\
-3.53 \\
-0.972 \\
-1.81\end{array}$ & & $\begin{array}{c}-0.0581 \\
- \\
- \\
-5.71 \\
-25.8 \\
-12.9 \\
-7.48 \\
-4.74 \\
-1.95 \\
-1.06 \\
-2.29\end{array}$ & & $\begin{array}{l}-0.858 \\
-2.24 \\
-1.37 \\
-7.29 \\
-20.7 \\
-40.7 \\
-6.65 \\
-4.99 \\
-2.91 \\
-1.02 \\
-2.11\end{array}$ & \\
\hline \multicolumn{10}{|c|}{$x_{1}=1$} \\
\hline $\begin{array}{l}\text { benzene / aniline } \\
\text { methanol / water } \\
\text { acetone / benzene } \\
\text { acetone / water } \\
\text { ethanol / benzene } \\
\text { 1-propanol / water } \\
\text { aniline / toluene } \\
\mathrm{CCl}_{4} \text { / methanol } \\
\mathrm{CCl}_{4} \text { / ethanol } \\
\mathrm{CCl}_{4} \text { / acetone } \\
\mathrm{CCl}_{4} \text { / aniline }\end{array}$ & $\begin{array}{l}298.15 \\
313.05 \\
298.15 \\
298.15 \\
298.15 \\
303.15 \\
293.15 \\
293.15 \\
293.15 \\
313.15 \\
298.15\end{array}$ & & $\begin{array}{c}-3.30 \\
0.0793 \\
0.317 \\
-17.6 \\
-1.31 \\
-0.775 \\
-1.16 \\
-2930 \\
-734 \\
-1.23 \\
-8.2\end{array}$ & & $\begin{array}{l}-2.80 \\
-0.680 \\
-0.646 \\
-4.51 \\
-3.57 \\
-2.93 \\
-7.50 \\
-22.5 \\
-19.7 \\
-2.92 \\
-5.61\end{array}$ & & $\begin{array}{l}-2.72 \\
- \\
- \\
-4.69 \\
-3.12 \\
-2.38 \\
-5.80 \\
-60.5 \\
-31.4 \\
-3.37 \\
-7.40\end{array}$ & & $\begin{array}{l}-3.07 \\
-0.715 \\
-0.672 \\
-5.35 \\
-3.11 \\
-2.59 \\
-6.14 \\
-53.5 \\
-37.7 \\
-3.14 \\
-5.2\end{array}$ \\
\hline
\end{tabular}


Table 6. Comparison of parameter values estimated with COSMO-SAC (at $\mathrm{T}=298.15 \mathrm{~K}$ ) and regressed values.

\begin{tabular}{|c|c|c|c|c|}
\hline System (1)/(2) & $b^{\alpha}(\mathrm{COSMO}-\mathrm{SAC})$ & $b^{\alpha}$ (regressed) & $b^{\beta}(\mathrm{COSMO}-\mathrm{SAC})$ & $b^{\beta}$ (regressed) \\
\hline toluene/water & 4319 & 2784.8 & 778.3 & 1079.9 \\
\hline$n$-pentane/water & 6141.2 & 5514.3 & 1620.1 & -1152 \\
\hline$n$-hexane/water & 6134.9 & 4322.3 & 1768.7 & -1248.8 \\
\hline$n$-heptane/water & 6166.3 & 3592.8 & 2085.5 & -786.27 \\
\hline$n$-octane/water & 6161.7 & 3737 & 2287.4 & -2032 \\
\hline$[\mathrm{hmim}]\left[\mathrm{BF}_{4}\right] /$ water & -15.167 & 463.1 & -4967.1 & 5525.9 \\
\hline [omim $]\left[\mathrm{BF}_{4}\right] /$ water & -500.9 & 501.1 & -4528.6 & 4717.7 \\
\hline$n$-hexane/nitroethane & 1363.9 & 6140 & 1112.9 & 5931.7 \\
\hline n-octane/ nitroethane & 1383.4 & 5577.6 & 1366.4 & 4561.2 \\
\hline $\begin{array}{l}\text { 2,2,4-trimethylpentane/ } \\
\text { nitroethane }\end{array}$ & 1173.7 & 5895.8 & 1055.1 & 4020.9 \\
\hline$n$-decane/ nitroethane & 1490.7 & 3152.3 & 1818.5 & 3444.1 \\
\hline
\end{tabular}


Table 7. Regressed parameters (all six) for considered systems. Parameter values with confidence ranges from eq. (26). In all cases phase $\alpha$ is rich in component 1 and $\beta$ rich in component 2.

\begin{tabular}{|c|c|c|c|c|c|c|}
\hline System (1)/(2) & $a^{\alpha}$ & $b^{\alpha}$ & $a^{\beta}$ & $b^{\beta}$ & $c^{\alpha}$ & $c^{\beta}$ \\
\hline \multirow[t]{2}{*}{ toluene/water } & -3.304 & 2736.6 & 5.718 & 1000.9 & -0.0023 & $(0.0999)$ \\
\hline & \pm 0.008 & \pm 2.22 & \pm 0.006 & \pm 1.716 & \pm 23.7 & \pm 2257.2 \\
\hline \multirow[t]{2}{*}{$n$-pentane/water } & -10.821 & 5514.3 & 15.307 & -1151.3 & $(0.005)$ & -0.0007 \\
\hline & \pm 0.001 & \pm 0.2 & \pm 0.001 & \pm 0.3 & \pm 21.871 & \pm 1452 \\
\hline \multirow[t]{2}{*}{$n$-hexane/water } & -7.042 & 4322.3 & 17.144 & -1248.8 & $3.11 \cdot 10^{-17}$ & 0 \\
\hline & \pm 0.002 & \pm 0.6 & \pm 0.003 & \pm 1.13 & \pm 29.6 & \pm 34256 \\
\hline \multirow[t]{2}{*}{$n$-heptane/water } & -4.764 & 3592.8 & 17.1 & -786.27 & $2.74 \cdot 10^{-15}$ & 0 \\
\hline & \pm 0.003 & \pm 0.9 & \pm 0.004 & \pm 1.27 & \pm 31.7 & \pm 215198 \\
\hline \multirow[t]{2}{*}{$n$-octane/water } & -6.886 & 4265.7 & 20.9 & -1454.4 & 0 & 0 \\
\hline & \pm 0.002 & \pm 0.6 & \pm 0.003 & \pm 0.7 & \pm 35.6 & \pm 240569 \\
\hline \multirow[t]{2}{*}[\mathrm{hmim}]{$\left[\mathrm{BF}_{4}\right] /$ water } & -1.230 & 460.99 & -12.225 & 4945.3 & -4.7 & -0.1 \\
\hline & \pm 0.218 & \pm 73.49 & \pm 0.303 & \pm 64.3 & \pm 146.3 & \pm 184.1 \\
\hline \multirow[t]{2}{*}[\text{omim}]{$\left[\mathrm{BF}_{4}\right] /$ water } & -1.402 & 409.87 & -15.719 & 5829.5 & -10.39 & $(0.03)$ \\
\hline & \pm 0.135 & \pm 45.77 & \pm 0.189 & \pm 40.04 & \pm 91.16 & \pm 114.64 \\
\hline \multirow[t]{2}{*}{$n$-hexane/nitroethane } & -19.554 & 6137.6 & -18.925 & 5931.7 & (3) & -7.998 \\
\hline & \pm 0.905 & \pm 241.1 & \pm 0.841 & \pm 225.6 & \pm 77.6 & \pm 80.8 \\
\hline \multirow[t]{2}{*}{$n$-octane/nitroethane } & -11.985 & 4045.8 & -8.850 & 3093.9 & $(60)$ & -40.00 \\
\hline & \pm 0.203 & \pm 54.7 & \pm 0.161 & \pm 43.1 & \pm 23.13 & \pm 28.78 \\
\hline \multirow{2}{*}{$\begin{array}{l}\text { 2,2,4-trimethylpentane } \\
\text { /nitroethane }\end{array}$} & -12.353 & 4032.8 & -8.354 & 2803.4 & $(10)$ & -5.005 \\
\hline & \pm 0.437 & \pm 114.6 & \pm 0.771 & \pm 190.3 & \pm 64.71 & \pm 132.18 \\
\hline \multirow[t]{2}{*}{$n$-decane /nitroethane } & -9.049 & 3309.1 & -9.973 & 3594.3 & $(10)$ & -8.01 \\
\hline & \pm 0.187 & \pm 48.9 & \pm 0.318 & \pm 85.5 & \pm 32.07 & \pm 63.91 \\
\hline
\end{tabular}


Reliable Correlation for Liquid-Liquid Equilibria Outside the Critical Region Łukasz Ruszczyński, Alexandr Zubov, John P. O’Connell, Jens Abildskov*

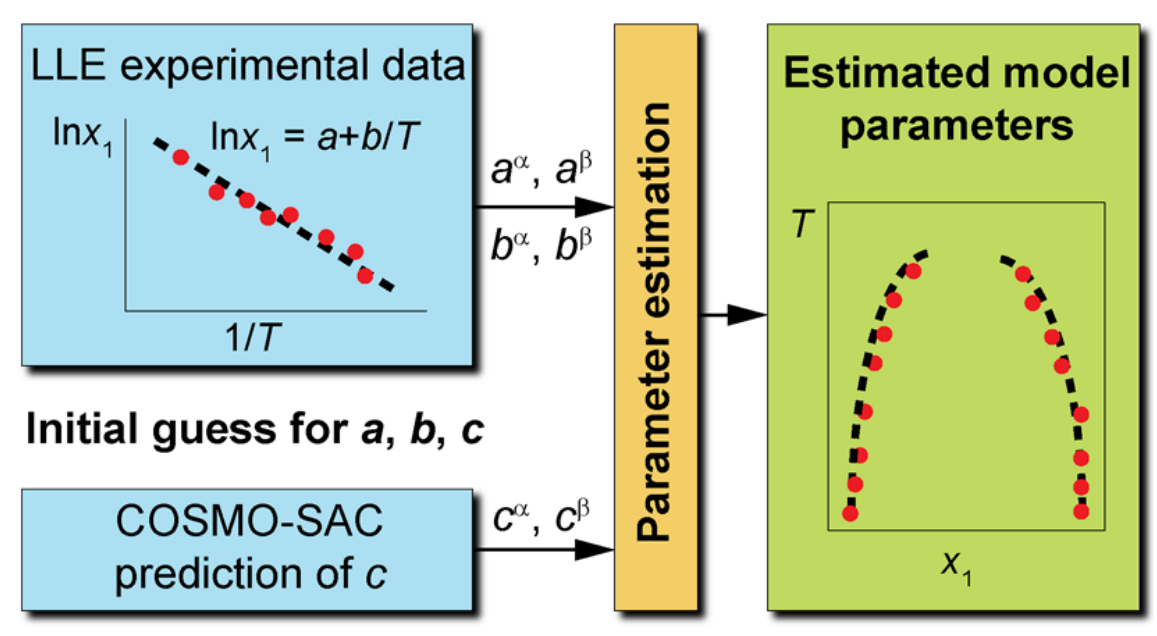

For Table of Contents use only 


\section{REFERENCES}

(1) Sørensen, J.M.; Arlt, W. Liquid-liquid equilibrium data collection, 1979, Chemistry Data Series, Vol. V, Part 1, DECHEMA.

(2) Marcilla A.; Reyes-Labarta J.A.; Olaya M.M. Should we trust all the published LLE correlation parameters in phase equilibria? Necessity of their assessment prior to publication. Fluid Phase Equilibria, 2017, 433, 243-252.

(3) Diky, V.; O’Connell, J. P.; Abildskov, J.; Kroenlein, K.; Frenkel, M. Representation and validation of liquid densities for pure compounds and mixtures. J. Chem. Eng. Data, 2015, 60, 3545-3553.

(4) Poling, B. E.; Prausnitz, J. M.; O’Connell, J. P. The Properties of Gases and Liquids. 2000, The McGraw-Hill Companies, Inc.

(5) Van Ness; H.C. Thermodynamics in the treatment of (vapor liquid) equilibria, J. Chem. Thermodyn. 1995, 27, 113-134.

(6) Cunico, L. P.; Ceriani, R.; Sarup, B.; O’Connell, J. P.; Gani, R. Data, analysis and modelling of physical properties for process design of systems involving lipids. Fluid Phase Equilib. 2014, 362, 318327.

(7) Kirkwood, J. G.; Buff, F. P. The statistical mechanical theory of solutions I. J. Chem. Phys. 1951, $19,774-777$.

(8) O'Connell, J. P. Thermodynamic properties of solutions based on correlation functions. Mol. Phys. 1971, 20, 27-33.

(9) O'Connell, J. P.; Haile, J. M. Thermodynamics: Fundamentals for Applications, 2005 Cambridge University Press.

(10) Prausnitz, J. M.; Lichtenthaler, R. N.; Gomes de Azevedo, E. Molecular Thermodynamics of Phase Equilibria, 1999, 3rd ed., Prentice Hall PTR, Upper Saddle River, New Jersey.

(11) Hsieh, C.-M.; Sandler, S. I.; Lin, S.-T. Improvements of COSMO-SAC for vapor-liquid and liquid-liquid equilibrium predictions. Fluid Phase Equilib. 2010, 297, 90-97.

(12) Klamt, A. Conductor-like screening model for real solvents - a new approach to the quantitative calculation of solvation phenomena. J. Phys. Chem. 1995, 99, 2224-2235.

(13) Mączyński, A.; Shaw, D. G. IUPAC-NIST Solubility Data Series. 81. Hydrocarbons with water and seawater-revised and updated. Part 5. C7 Hydrocarbons with water and heavy water. J. Phys. Chem. Ref. Data 2005, 34, 1399-1487.

(14) Seber, G. A. F.; Wild, C. J. Nonlinear regression. 1989 Wiley, New York.

(15) Mączyński, A.; Shaw, D. G. IUPAC-NIST Solubility Data Series. 81. Hydrocarbons with water and seawater-revised and updated Part 1. $\mathrm{C}_{5}$ Hydrocarbons with water. J. Phys. Chem. Ref. Data 2005, 34, 441-476.

(16) Mączyński, A.; Shaw, D. G. IUPAC-NIST Solubility Data Series. 81. Hydrocarbons with water and seawater-revised and updated. Part 4. $\mathrm{C}_{6} \mathrm{H}_{14}$ Hydrocarbons with water.

J. Phys. Chem. Ref. Data 2005, 34, 709-753.

(17) Mączyński, A.; Shaw, D. G. IUPAC-NIST Solubility Data Series. 81. Hydrocarbons with water and seawater-revised and updated. Part 7. $\mathrm{C}_{8} \mathrm{H}_{12}-\mathrm{C}_{8} \mathrm{H}_{18}$ Hydrocarbons with water. J. Phys. Chem. Ref. Data 2005, 34, 2261-2298.

(18) Maia, F. M.; Rodriguez, O; Macedo, E. A. LLE for (water + ionic liquid) binary systems using (Cxmim)(BF4) $(\mathrm{x}=6,8)$ ionic liquids. Fluid Phase Equilib. 2010, 296, 184-191.

(19) Królikowska, M. (Solid + liquid) and (liquid + liquid) phase equilibria of (IL + water) binary systems. The influence of the ionic liquid structure on mutual solubility IL + water. Fluid Phase Equilib.

2014, 361, 273-281. 
(20) Domańska, U.; Rękawek, A.; Marciniak, A. Solubility of 1-alkyl-3-ethylimidazolium-based ionic liquids in water and 1-octanol. J. Chem. Eng. Data 2008, 53, 1126-1132.

(21) Martins, M. A. R.; Neves, C. M. S. S.; Kurnia, K. A.; Luis, A.; Santos, L. M. N. B. F.; Freire, M. G.; Pinho, S P.; Coutinho, J. A. P. Impact of the cation symmetry on the mutual solubilities between water and imidazolium-based ionic liquids. Fluid Phase Equilib. 2014, 375, 161-167.

(22) Hwa, S. C. P.; Techo, R.; Ziegler, W. T. Solubility of nitroethane in hydrocarbons. J. Chem. Eng. Data 1963, 8, 409-411.

(23) Renon, H.; Prausnitz, J. M. Local compositions in thermodynamic excess functions for liquid mixtures, AIChE J. 1968, 14, 135-144.

(24) Hofman T; Reda, M.; Gliński, M. Liquid-liquid equilibrium in binary systems of isomeric C-8 aliphatic monoethers with nitromethane. Fluid Phase Equilib. 2013, 356, 271-276.

(25) Sherman, S. R.; Suleiman, D.; Hait, M. J.; Schiller, M.; Liotta, C. L.; Eckert, C. A.; Li, J.; Carr, P. W.; Poe R. B.; Rutan S. C. Correlation of partial molar heats of transfer at infinite dilution by linear solvation energy relationship. J. Phys. Chem. 1995, 99, 11239-11247.

(26) Marongiu, B.; Porceda, S.; Kehiaian, H.V. Calorimetric study of nitro group interactions in alkane solutions. Comparison with DISQUAC predictions. Fluid Phase Equilib. 1993, 87, 115-131.

(27) Hovorka, Š.; Dohnal, V.; Carrillo-Nava, E.; Costas, M. Infinite dilution activity coefficients for benzene and toluene in water and in aqueous solutions of protein denaturants urea and guanidine hydrochloride. J. Chem. Thermodyn. 2000, 32, 1683-1705.

(28) Wooley, R. J.; O'Connell, J. P. A database of fluctuation thermodynamic properties and molecular correlation function integrals for a variety of binary liquids. Fluid Phase Equilib. 1991, 66, 233-261.

(29) Matteoli, E.; Lepori, L. Solute-solute interactions in water II. Analysis through the Kirkwood-Buff integrals for 14 organic solutes. J. Chem. Phys. 1984, 80, 2856-2863.

(30) Nishikawa, K.; Kodera, Y.; Kojima, T. Fluctuations in the particle number and concentration in the Kirkwood-Buff parameters of $t$-butyl alcohol and water mixtures studied by small angle X-ray scattering. J. Phys. Chem. 1987, 91, 3694-3699.

(31) Hamad, E. Z.; Mansoori, G. A.; Matteoli, E.; Lepori, L. Relations among concentration fluctuation integrals in mixtures (theory and experiments). Z. Phys. Chem. N. F. 1989, 162, 27-45.

(32) Zaitsev, A. L.; Petrenko, V. E.; Kessler, Y. M. Solution structure and Kirkwood-Buff: informativity and sensitivity to specific interactions. J. Solution Chem. 1989, 18, 115-130.

(33) Abildskov, J.; Gani, R.; Rasmussen, P.; O’Connell, J. P. Analysis of infinite dilution activity coefficients of solutes in hydrocarbons from UNIFAC. Fluid Phase Equilib. 2001, 181, 163-186.

(34) Vrbka P.; Dohnal V.; Arlt W. Limiting Activity Coefficients by Comparative Tensimetry: 1Propanol and 1-Butanol in Heptane and in Octane. J. Chem. Eng. Data, 2004, 49, 867-871.

(35) Vrbka P.; Hauge B.; Frydendal L.; Dohnal V. Limiting Activity Coefficients of Lower 1-Alkanols in n-Alkanes: Variation with Chain Length of Solvent Alkane and Temperature. J. Chem. Eng. Data, 2002, 47, 1521-1525.

(36) Hovorka S.; Dohnal V.; Roux A.H.; Roux-Desgranges G. Determination of temperature dependence of limiting activity coefficients for a group of moderately hydrophobic organic solutes in water. Fluid Phase Equilibria, 2002, 201, 13-164. 